\title{
Subsidizing Altruism in Living Organ Donation
}

Kurt E. Schnier*; Robert M. Merion; Nicole Turgeon; David Howard

*Corresponding Author: Department of Economics; University of California, Merced; 5200 North Lake Road; Merced CA 95343. email: kschnier@ucmerced.edu. Phone: (209) 205-6461. The data reported here have been supplied by the United Network of Organ Sharing as the contractor for the Organ Procurement and Transplantation Network. The interpretation and reporting of these data are the responsibility of the authors and in no way should be seen as an official policy of or interpretation by the OPTN or the U.S. Government. We thank Ketki Sheth, Gregory Wright, the Editor and three anonymous referees who provided valuable comments on our paper. All errors and omissions remain the authors' responsibility.

\section{Abstract}

The current supply of deceased donor organs is insufficient to meet the growing demand for transplantable organs. Consequently, candidates for kidney transplantation are encouraged to find a living donor. In 2008 the Department of Health and Human Services began to reimburse donor's travel-related expenses via the National Living Donor Assistance Center (NLDAC). Using variation in transplant centers' applications for donor assistance, we use a difference-in-difference model to estimate the relationship between NLDAC and living donor kidney transplants. We find that among participating transplant centers the program increased the number of living donor kidney transplants by approximately $14 \%$.

Keywords: Transplantation, Living Donors, Financial Incentives

JEL Codes: I12, I18, D64

\section{Introduction}

There are over 615 thousand patients with End Stage Renal Disease (ESRD) in the United States (USRDS

This is the author manuscript accepted for publication and has undergone full peer review but has not been through the copyediting, typesetting, pagination and proofreading process, which may lead to differences between this version and the Version of Record. Please cite this article as doi: $10.1111 /$ ecin. 12488

This article is protected by copyright. All rights reserved. 
2013). The costs of treating these patients accounts for over $\$ 40$ billion in annual treatment costs (NKUDIC 2014). Most of these patients are treated with dialysis, but patient outcomes improve and the costs are lower for patients who receive a kidney transplant. Currently, there are not enough kidneys recovered from deceased donors to satisfy the demand for organs and many patients are encouraged to seek a living donor kidney transplant. In 2012 deceased donors provided 10,868 organs and 5,619 patients received kidneys from living donors (OPTN 2014). However, during this same time period 30,274 patients were added to the waiting list that already included 88,874 patients at the beginning of the year and 11,012 patients either died while waiting for an organ or were removed due to poor health (OPTN 2014). Clearly, the current organ procurement and allocation mechanisms are not sufficient to meet the growing demand for transplantable organs.

Though ethical considerations have prevented direct monetary incentives to donors, there is a growing concern that the costs of being a living donor may be acting as a disincentive and preventing donations (Fisher et al. 2015; Delmonico et al. 2015). While the National Organ Transplant Act (NOTA) prohibits payments that provide incentives for donation, it does not preclude payments to donors to cover the costs associated with donating. These costs, which include travel to and from a transplant center, may discourage potential living donors from agreeing to donate an organ. In 2004 Congress authorized the U.S. Department of Health and Human Services to create a program to reduce the financial disincentives associated with living organ donation by covering low income living donors' non-medical transplant-related costs (e.g., travel and incidental expenses). In 2008 the Federally-funded National Living Donor Assistance Center (NLDAC) began to pay donation-related expenses for qualified living donors. Using variation in transplant centers' applications for donor assistance, we estimate the impact of NLDAC on the number of living organ donors. We find that the program led to a $14 \%$ increase in the number of living organ donors at participating centers providing an annual benefit to society of approximately \$252 million.

Our analysis is complicated by the fact that a center's application for donor assistance is not exogenous and therefore it is difficult to claim that the NLDAC program caused the observed increase in living organ donors. A center's ability to file for donor assistance at any time introduces a potential reverse causality. In our analysis we 
explore a number of different empirical specifications to minimize the impacts of reverse causality and to investigate the sensitivity of our results to alternative structural assumptions. Our results are robust to these alternative specifications and the falsification tests we utilize further support our findings. This said, we can not make any claims about what would happen if a non-enrolled center decided to start filing for donor assistance with NLDAC. However, finding a positive association between NLDAC and living organ kidney donation is an important finding that will contribute to our growing understanding of individual incentives within our current organ transplant market.

The economics literature has naturally focused on prohibitions against paying donors, living or deceased, as the principal cause of the shortage of transplantable organs (Cohen 1989; Adams et al. 1999; Becker and Elias 2007; Cohen 1989; Kaserman and Barnett 2002; Welington and Whitmire 2007). While there is a growing support for the use of donor incentives in the transplant community (Peters 1991; Gaston et al. 2006; Howard (RJ) 2007), provision of any type of "valuable consideration" violates NOTA and many transplant professionals, clergy, and even patients continue to find payment for donation "repugnant" (Roth 2007). ${ }^{1}$ However, because the NLDAC program focuses on covering donation related expenses it does not violate NOTA. Therefore, NLDAC provides a step toward reducing the financial disincentives associated with being a living organ donor.

Aside from the NLDAC program there are other incentive structures that provide limited financial support for living organ donation. A number of U.S. states permit organ and bone marrow donors to claim tax credits or deductions for donation-related expenses and grant paid leave for organ donors (National Kidney Foundation

1 The primary reason for opposing a direct market for organs within the transplant community is based on ethical considerations (Pellegrino 1991; Delmonico et al. 2002; Israni et al. 2004; Steinbrook 2005; Rothman 2002). 
2013). ${ }^{2}$ The current literature has found that these programs have not increased the rate of living organ donation (Boulware et al. 2008; Lacetera et al. 2014; Venkataramani et al. 2012; Wellington and Sayre 2011). However, the research of Lacetera et al. (2014) has illustrated that these programs have successfully increased the rate of bone marrow donation. They argue that the tax and leave benefits provide a large enough financial benefit to compensate for the less medically intrusive bone marrow donation procedures, but not enough to increase living organ donation, which requires a major surgical procedure.

One concern about paying donors is that the extrinsic incentives will crowd out the intrinsic motivation and prosocial behavior (Rothman and Rothman 2006; Danovitch and Leichtman 2006), possibly leading to a net reduction in the supply of organs. However, this concern is not applicable in our environment as the NLDAC is targeted at reducing the costs of being a donor versus providing a reward. Furthermore, recent empirical research on the use of financial incentives to increase blood donations, which also relies on the altruistic motives of the donor, have not found results consistent with the crowding out hypothesis (Lacetera et al. 2012, 2013; Lacetera and Macis 2013). Instead this literature has illustrated a strong correlation between financial incentives and the rate of blood donation. ${ }^{3}$ Additionally, recent research conducted by Ferguson $(2013,2015)$ has focused more directly on the type of altruism blood donors possess and found that they are either warm-glow giviers (Andreoni 1990) or are reluctant altruists in that their cooperation rates are high when free-riding is also high (Ferguson 2013 , 2015). Ferguson argues that both of these types of individuals will most likely increase donations if a

2 These incentive programs are consistent with the growing support in the transplant community to make sure that the donor is left no worse off then they were prior to electing to be a donor (Boulware et al. 2006; Israni et al. 2004; Fox 2006; Gaston et al. 2006).

3 The crowding out hypothesis has been theoretically studied in the living organ market by Epstein (2008) and the deceased donor market by Byrne and Thompson (2001). 
financial incentive is provided via a charitable instrument versus direct financial compensation. By compensating organ donors for costs related to donation, but not leaving them better off than if they had not donated, NLDAC should not lead to crowd out.

Although direct financial compensation remains off the table, some countries, including the U.S., are experimenting with market-like mechanisms for increasing the supply of living organ donors. ${ }^{4}$ Based in part on the work of Roth and colleagues (Roth et al. 2004, 2005, 2007), the U.S. Organ Procurement and Transplantation Network recently implemented the Kidney Paired Donation Pilot Program. ${ }^{5}$ The program permits kidney transplant candidates with immunological-incompatible living donors to swap donors. In the absence of the program, the candidates would have to undergo more risky incompatible transplants or join the waiting list for a deceased donor organ. Changes in the organ allocation rules have also been enacted in an effort to increase organ donation. For instance, in 2008 the Israeli Parliament passed a law that gives priority on the deceased donor transplant waiting list to persons who have registered to become organ donors themselves. Early evidence indicates that donation rates increased after the law went into effect (Lavee and Brock 2012). ${ }^{6}$

${ }^{4}$ For a more detailed discussion of the public policy debate see Howard (DH) (2007) who provides a summary of the pros and cons of different public policies that could be utilized to increase organ donation: financial incentives for deceased donors, presumed consent, mutual insurance pools and payment for living donors.

${ }^{5}$ Ross et al. (1997) conducted a detailed analysis of the ethics of a paired-kidney exchange and they concluded that it did not violate the "valuable consideration" clause of NOTA and that it satisfied the current ethical standards within the transplant community. NOTA was subsequently amended in 2007 to permit paired-kidney donations.

${ }^{6}$ The efficacy of the different public policies that could be utilized to incentivize deceased donor organs, changes 
The following section discusses the transplantation environment in more detail. Section Three discusses the NLDAC program, focusing on the nature of the financial incentives offered and on program eligibility. In Section Four we discuss the data used to investigate the association between NLDAC and living donor kidney transplants. Section Five outlines the difference-in-difference model estimated and Section Six illustrates two falsification tests used to further validate our results. The final section summarizes our results and provides some additional avenues for fruitful research on increasing organ donation.

\section{Transplantation Environment}

Patients suffering from ESRD can obtain organs from either a deceased or living organ donor. The mechanisms for obtaining these two types of organs are different. The deceased donor market is determined by the available supply of deceased donors. Upon death a deceased's next-of-kin are contacted to determine whether or not they are willing to donate the deceased's organs. If they agree, or if the decedent has a documented antemortem expression of first-person donation consent, the organs are offered to the local Organ Procurement Organization (OPO) which initiates a match run. The match run orders patients on the waiting list according to a prespecified algorithm. Offers are made from this list to transplant teams, who elect to accept or decline the organ offer for their patient based on medical criteria. The sequence of offers is determined by a point-based system that is heavily influenced by the length of time that each patient has been waiting for an

in the priority rule as well as the default donation decision, have also been experimental investigated (Kessler and Roth 2012; Li et al. 2013). The central findings of this research are that utilizing a priority rule will increase organ donation (Kessler and Roth 2012) and changing the default donation policy from an opt-in to an opt-out program would also increase organ donation (Li et al. 2013). There is also a growing literature on the impact that public policies have on organ donation rates, such as presumed consent laws (Beard et al. 2004), the repeal of helmet laws (Dikert-Conlin et al. 2011) and the current loopholes in priority rule regulations (Kessler and Roth 2013). 
organ. $^{7}$

The living donor system is substantially different from the deceased donor system because the patient actively searches for a potential volunteer donor to be screened by the transplant team to determine their medical, surgical, and psychosocial suitability. If the living donor is deemed suitable, the transplant process goes forward. In the case that a potential living donor is not suitable the National Kidney Registry facilitates a process that matches a patient with other potential donors in an effort to conduct two-way and three-way exchanges, sometimes longer chains, to more efficiently utilize the available living donor organ pool (Roth et al. 2004, 2005, 2007). Although economists have argued that the costs of seeking a living donor match are very low and warrant an increase in effort to increase this pool of donors (Thorne 1996), there is still a reluctance among those in need to request organs from others. Presumably, this is a result of large non-financial costs associated with seeking a living organ donation. ${ }^{8}$

The number of deceased and living kidney donors as well as transplants conducted between 1988 and 2012 are illustrated in Figure 1. The total number of kidney donors has increased substantially since 1988, with a total increase of approximately $129 \%$. However, the rate of growth over the past decade has stalled. The rate of increase in the living donor pool far outpaced the deceased donor pool until the early 2000s. The number of

7 A primary exception to this rule is if the patient-donor histocompatibilties possess a zero antigen mismatch, which implies that an organ is a near perfect fit for the patient with an extremely low probability of rejection. If this is the case a patient on the waiting list with a zero antigen mismatch will be given priority over others.

8 More recently Howard (2011) has argued that there are large non-financial costs associated with eliciting a donor. He illustrated that the waiting time for an organ functions as a price for deceased donor organs for patients waiting for a transplant. 
deceased donors increased by 91\% between 1988 and 2012, whereas the increase in living donors was 209\% (OPTN 2014). The number of transplants conducted clearly illustrates that deceased donor transplants are more prevalent than living organ donor transplants. This is because each deceased donor results in an average of 1.55 deceased donor transplants, as both of their kidneys are often recovered for transplantation, and by definition a living organ donor only provides one organ for transplantation. This ratio has decreased substantially from 1.82 in 1988 to 1.46 transplants per a donor in 2012 (OPTN 2014). In 2012, 10,868 deceased donor kidney transplants were conducted from 7,421 deceased donors and 5,619 living donor kidney transplants conducted (OPTN 2014).

Living organ donors may incur substantial travel expenses as part of the donation process. Candidate donors must travel to the transplant center to be evaluated and return for surgery and post-surgical follow-up visits if they are eligible to donate. Many travel with a relative or friend for support and assistance, adding to the cost. Even when donors live in the same city as their recipient, they may need to travel if nearby hospitals do not offer transplant services, if the recipient prefers an out-of-town center, or if the recipient's insurer restricts coverage to procedures performed in out-of-town facilities. Recipients are allowed to reimburse donors for expenses, and some hospitals provide low cost lodging options. However, most donors pay some or all of their travel costs out-of- pocket (McCune et al. 2004). These costs present a substantial hardship to many donors (Shover et al. 1997) and may discourage individuals from donating in the first place.

\section{NLDAC Program}

The Organ Donation and Recovery Improvement Act (ODRIA) of 2004 (U.S.C. 274f) authorized the Department of Health and Human Services to establish a program to reimburse travel-related and other incidental expenses of living donors and persons undergoing evaluation for living donation. The program, named the National Living Donor Assistance Center (NLDAC), is operated jointly by the University of Michigan and the American Society of Transplant Surgeons under a cooperative agreement with the Health Resources and Services Administration. Transplant centers could enroll in the NLDAC program starting in October 2007, and financial assistance was initiated in January 2008. The NLDAC program is a means-tested program. Qualifying donors must have an income below $300 \%$ of the federal poverty level. NLDAC grants exceptions if donors can demonstrate 
financial hardship. NLDAC provides reimbursement for donation-related travel and incidental expenses up to $\$ 6,000$. NLDAC does not compensate donors for lost wages or out-of-pocket medical expenses.

The number of applications to NLDAC has been increasing each year since its inception. NLDAC received over 900 applications in the 2013 fiscal year and the number of donors receiving assistance increased from 164 in 2008 to 426 in 2012 . Of the 3,918 applications received from fiscal years 2008 through the end of fiscal year 2013, 148 were not approved, 221 were withdrawn, and 38 missed the submission deadline. 1,133 applicants were approved for funding but were ineligible to donate. ${ }^{9}$ At the end of the fiscal year in 2013 donation surgery was pending for 443 applicants. The total outlay of funds in the fiscal year 2013 was $\$ 1.8$ million and the median income of aid beneficiaries was approximately $\$ 34,000$. Fifty-seven percent of NLDAC applicants were employed full time. The approved donors received an average of $\$ 2,800$ in assistance.

Potential donors cannot apply directly to NLDAC. Instead, they apply through transplant centers that have registered with NLDAC. The first step in the process requires centers to enroll in the program and register with NLDAC. The first month that a center could enroll was in October 2007. In order to increase enrollment, the NLDAC staff promoted the program to transplant center staff (i.e.,transplant coordinators, social workers, physicians) at various professional meetings. Following enrollment a center could elect to participate in the program by submitting an application with NLDAC for donor assistance. Participation could vary across years as some centers may elect to submit applications in one year and not in another. Therefore, participation can be defined based on whether or not they participated in the past or are an active participant in the program (i.e., filed with NLDAC in the current year). This said, enrollment and participation are not exogenous and efforts must be taken to account for potential selection effects into the program.

9 Potential donors undergo a rigorous screening process. Persons with hypertension, diabetes, mental health problems, or other chronic conditions cannot donate organs. 
Figure 2 illustrates the enrollment and participation rates. Enrollment is defined as when a center registered with the NLDAC and centers rapidly enrolled in the program. Enrollment, defined as $N L D A C_{i t, \text { enrolled, }}$ exceeded $87 \%$ of all U.S. living donor transplant programs within six months. At the end of 2012 enrollment was approximately $94 \% .{ }^{10}$ If we define participation as beginning when a center filed their first application with

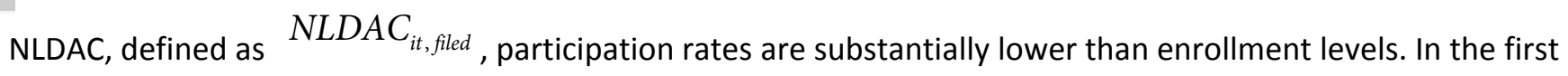
year of the program approximately $46 \%$ of the centers participated in the program and the percentage increased to slightly over $80 \%$ by the end of the data period. If we define participation year by year, (by including a center as participating in a given year only if one or more applications were filed within that given year), defined as

$N L D A C_{i t, a c t i v e}$, results in an even lower participation rate, reaching a maximum of approximately $63 \%$ by the end of our data period.

Centers that enroll in NLDAC have greater transplant volume than non-enrolling centers and they may differ along unobserved dimensions as well. Furthermore, centers that enroll may have a greater capacity to benefit from the NLDAC program. Enrolled centers account for $99 \%$ of the total living donor transplants observed in our data set. In most program evaluation studies researchers are trying to extrapolate results from a small number of treated units to a much larger group of units that are potentially eligible for treatment. Selection into treatment is problematic, even if researchers observe pre-program outcomes in the treated units. In our case, the goal of the analysis is simply to estimate the relationship between NLDAC and the volume of living donor transplants among participating centers. We make no claims about what would happen if a non-enrolled center decided to start filing claims. We include non-enrolled centers in the study to control for factors common to all

10 In calculating the percentage of enrolled centers we only look at those centers that have a positive number of patients on their kidney waiting list. 
centers that affected trends in the volume of living organ donors. A finding that NLDAC is positively associated with transplant volume among enrolled centers would be an important finding even if enrollment in NLDAC would have no effect on centers that did not enroll. Our identification strategy discussed in the empirical modeling section outlines the methods we use to mitigate this selection effect.

One other aspect of the transplant environment that must be accounted for in our analysis is the regulatory status of the transplant center. The Centers for Medicare and Medicaid Services (CMS) monitor the performance of each transplant center under their Conditions of Participation (CoP) standards that took effect on June 28, 2007, shortly before NLDAC was launched. The CoP measures use each center's one-year graft and patient survival statistics to determine whether the center is performing adequately. Therefore, these regulatory standards may also alter a center's volume of living organ transplantation. ${ }^{11}$

\section{Data Description}

The data for our analysis come from three separate sources. From the Organ Procurement and Transplantation Network (OPTN) we obtained information on all the patients waiting for a kidney transplant and the donors who provided organs between January 1, 2003 and December 31, 2012. We merged this data with NLDAC records on the volume of filings by year and center as well as the date that the transplant center enrolled in NLDAC. We obtained data on a centers' regulatory status (meeting versus not meeting CMS standards) from the Scientific Registry of Transplant Recipients (SRTR). Our analysis focuses on 239 unique transplant centers that

${ }^{11}$ Details regarding the information used by the CMS CoP to determine a center's regulatory status are contained in Abecassis et al. (2008) and Dickinson et al. $(2006,2008)$. Additional details, and the behavioral impacts of the CMS CoP are contained in Schnier et al. (2013a, 2013b), Ouayogode (2014) and Cox et al. (2012). 
performed non-pediatric living donor kidney transplants between 2003 and 2012. ${ }^{12}$ There were 28,680 observations at the transplant center-month level. We further restricted our sample to only those center-month observations where the center had a non-zero number of patients currently waiting for a kidney transplant at the center to ensure that we focused on only those centers that were actively conducting kidney transplants during this time period. This restriction resulted in a data set containing 26,749 center-month observations. ${ }^{13}$

In the following discussion we compare trends in the number of living donor transplants conducted between enrolled, filing and non-filing centers, all defined various ways, to compare pre-NLDAC trends in transplant volume and to look for graphical evidence of a NLDAC treatment effect. To illustrate the structural differences between centers that did and did not participate we regressed the number of living donor transplants conducted each month on a set of center-level fixed effects to de-mean the data and plotted the resulting residuals two different ways. To illustrate the differences at the monthly level we plot the average residual for our defined treatment and control group over the time horizon of the data. Our alternative plot aggregates the residuals up to the annual level to provide a more smoothed illustration of the structural differences. The residual plots allow for us to graphically illustrate the differences between our treatment and control groups, while controlling for center-level heterogeneity (i.e., level effects). This helps to provide initial evidence of the relationship between NLDAC and living organ donation. One factor common among all of the figures illustrated is that they trend downwards because during our time period studied the number of living donor transplants fell from 6,470 to 5,619, see Figure 1 (UNOS 2014).

Figure 3 contains the average residual plots for those centers that elected to enroll in the NLDAC program

12 A pediatric center is defined as a center that specializes in and conducts only pediatric kidney transplants.

13 Our preliminary analysis indicated that our estimates were robust to the exclusion of these observations. 
and those that did not enroll in the program. The residual plots illustrate that prior to the NLDAC program being initiated those centers who enrolled and did not enroll in NLDAC possessed similar downward trends. However, following the creation of the NLDAC those centers that enrolled in the program deviated substantially from this trend in the initial years following enrollment. There are a number of reasons why centers differed in their tendency to enroll and their level of participation conditional on enrollment. NLDAC staff attended transplant conferences and distributed promotional materials to encourage enrollment, but the intensity of contact varied across centers. Centers with more to gain from the program (i.e., large centers) may have been among the first to enroll. Furthermore, NLDAC tried to keep the eligibility criteria and verification process as simple as possible while complying with the requirements of the authorizing legislation. However, participation required training to understand how to complete application forms, compile the relevant documentation, and instruct patients about the reimbursement process. This was a learning process that may have influenced why a center elected to participate or not at a given point in time. Another factor that may have influenced participation is variation in the transplant center's staff experience levels and internal turnover. It is for these reasons that we need to be careful how we define "participation" in our model.

Expanding our definition of our treatment and comparison groups, we further partition the data by focusing on only those centers that enrolled in NLDAC and elected to either file a claim at some point in time following enrollment (i.e., participated in the NLDAC program) or did not elect to file a claim at any point in time during our study. These are both time invariant groupings that define participation as any activity in the post-NLDAC time period. The plot of the mean monthly and year residuals for these two groups is contained in Figure 4. Although our definition of treatment and comparison group has changed, we observe a similar pattern to that observed in Figure 3. In the pre-NLDAC period those centers who enrolled and filed at least once with NLDAC in the post-NLDAC period and those centers who enrolled but never filed a claim with NLDAC illustrate a similar downward data trend. Furthermore, we again observe the treatment effect among those centers that enrolled and filed with NLDAC in the years immediately following the creation of the NDLAC. However, the magnitude of this treatment effect is smaller than that observed in Figure 3, which would be expected given that we are an essence purging a sizable proportion of the effect associated with enrolling with the NLDAC. 
We can not differentiate the pre-NLDAC trends for centers that enrolled and filed at least once with NLDAC from centers that actively filed with NLDAC in a given year because the later group is subset of the former group. However, we can differentiate the post-NLDAC trends between these two respective groups and the residual plots are contained in Figure 5. The trends in the data provide our most concrete illustration of the treatment effects generated by the NLDAC. The pre-NLDAC trends are identical to those observed in Figure 4 as the treatment and comparison are the same. In the post-NLDAC period we partition the centers that enrolled and filed with NLDAC at some point in time following the creation of the NLDAC into those centers that filed in a given year and those that did not in the same year. The post-NLDAC trends illustrate that those centers in the later group possess a very similar trend to those centers that enrolled but never filed with NLDAC. However, once a center elects to file with NLDAC there is a substantial increase in the number of transplants conducted. This is the most restrictive specification we investigate as it divides the actively participating centers, those enrolled and filing with NLDAC, into those that did not file with NLDAC in a given year and those that did in a given year. Given that a center's participation may vary across years, it allows for a given center to serve as their own control in a later time period when they elect to not enroll, provided that they elect to not file in a post-NLDAC year. ${ }^{14}$ Partitioning the data set in this way illustrates transplant center behavior that is consistent with the hypothesis that NLDAC increased living donor kidney transplants for those centers that were actively filing versus not actively filing in a given year. The precise nature of our identification strategy will be discussed in more detail in the following section.

Table 1 illustrates the descriptive statistics for the data used in our analysis. We elected to partition the data based on whether or not a center filed at least once with NLDAC in the post-NLDAC time period. The treated group contains all those centers that filed at least once in the post-NLDAC period. The untreated group contains

${ }^{14} 46 \%$ of the centers that filed with the NLDAC did not file in every year after the inception of the NLDAC. 
all centers that enrolled and never filed as well as those that never enrolled. The data set is also further partitioned based on the pre-NLDAC and post-NLDAC time periods. In addition, to the means and standard deviations we present the normalized differences proposed by Imbens and Rubin (2015) and discussed in Imbens and Wooldridge (2009). ${ }^{15}$ All of the variables illustrated, except for the monthly number of transplants, the number of patients on the waiting list and patient BMI were calculated as the percentage of patients on a center's waiting list that possessed a particular characteristic (i.e., previous kidney transplant, male, etc.) at the beginning of the month-year observation period.

The variables contained in Table 1 were used as covariate controls in our regression models discussed in the upcoming section. These variables were selected as they provide important demographic and health related information that may influence the rate of organ transplantation at the center. Data on a center's waiting list helps to provide a measure of demand at each center that may influence their rate transplantation. Information about the gender and ethnic mix as well as the percentage who work, have higher education and are utilizing publicly funded medical care provide important socioeconomic data. The remaining covariates help to control for the health status of patients at the center (i.e., functional status, diabetes, previous transplants, BMI, hypertension, etc..) as well as the unique patient characteristics that may help explain the difficulties associated with transplantation (i.e., panel reactive antibodies (PRA) greater than 80). For instance, whether or not a patient has previously received an organ transplant is a factor in the allocation mechanism used to provide deceased donor organs. A patient's functional status helps to provide a measure of the urgent needs of the patients on the waiting list. Lastly, patients with a PRA level greater than 80 are more difficult to find a suitable organ match.

15 The normalized difference is used in lieu of the $t$-test because large samples generate statistical differences. Imbens and Rubin (2015) rule of thumb is that a value greater than 0.25 makes the linear regression methods utilized to test for treatment effects sensitive to specification. 
In the pre-NLDAC time period the treated centers conducted approximately 2.8 living donor kidney transplants per a month (standard deviation of 3), whereas the untreated centers conducted approximately 0.8 (standard deviation of 1.2). The treated centers also possessed a substantially larger number of patients on the waiting list in the pre-NLDAC period with approximately 332 wait listed patients (standard deviation of 400), whereas the untreated centers possessed only 111 patients (standard deviation of 184) on their waiting list. Centers that enrolled in the NLDAC program were clearly higher volume transplant centers. Patients at treated centers were more likely to have a higher $\mathrm{BMI}$, a previous kidney transplant, a college education, employment income and to be on the expanded donor waiting list. These centers also had a lower percentage of waiting list patients utilizing public payment mechanisms. The other covariates were similar across the participating and nonparticipating centers.

The differences observed in the pre-NLDAC period similarly arise in the post-NLDAC time period, with the exception that the nonparticipating centers in the post-NLDAC period also possessed a distinguishably higher percentage of males on their waiting list than participating centers. The differences illustrated highlight the importance of including these covariate controls in our regression modeling. Another interesting feature illustrated in the data is that the average monthly rate of living donor kidney transplants fell in the post-NLDAC time period for both the participating and nonparticipating centers. However, this shift is not discontinuous and the reduction is roughly the same for the participating and nonparticipating centers. Therefore the continuous nature of the data trends are preserved, validating our use of a difference-in-difference model. ${ }^{16}$ The participating centers conducted approximately 2.6 living donor kidney transplants (standard deviation of 3), whereas the nonparticipating centers conducted approximately 0.5 living donor kidney transplants (standard deviation of 1) in the post-NLDAC period. These trends are consistent with the number of living organ kidney

${ }^{16}$ Further defense of the parallel trends is empirically illustrated in the Empirical Models and Results section. 
donors illustrated in Figure 1. At this same time the average waiting list at the participating centers increased to 455 patients (standard deviation of 547) and 130 at nonparticipating centers (standard deviation of 144).

\section{Empirical Models and Results}

We estimated the impact of the NLDAC program on the number of living donor transplants in center $i$ at time $t, O_{i t}$, using a Poisson regression model with center and month-year fixed effects. The model parallels the residual plots in Figure 3 through $5 .{ }^{17}$ The model is,

$$
O_{i t}=\beta_{1} \text { Wait }_{i t}+\beta_{2} C M S_{i t \mid p a t / g r a f t}+\gamma_{1} N L D A C_{i t, \text { enrolled }}+\delta_{i t} X_{i t}+\alpha_{i}+\theta_{t}+e_{i t}
$$

The variable Wait $_{i t}$ is the number of patients on center $i^{\prime} s$ waiting list at the beginning of month $t$, $C M S_{i t \mid p a t / g r a f t}$ is a binary variable that takes a value of one if center $i$ does not meet the CMS CoP for either one-year graft survival or patient survival in period $t$ (the two CMS CoPs represent separate regressions) and $N L D A C_{i t, e n r o l l e d}$ is a binary variable that takes a value of one if center $i$ enrolled in the NLDAC program in period $t$. The matrix $X_{i t}$ contains a set of center-level covariate controls (see Table 1) that characterize the composition of a transplant center's waiting list at the beginning of time period $t . \alpha_{i}$ is a center fixed effect to

17 In our preliminary regression modeling we also explored using a negative binomial specification to estimate the count model. The results from the negative binomial model are qualitatively similar to those observed in the Poisson regression. Therefore, we elected to only retain the Poisson regression modeling results. The negative binomial results can be obtained from the corresponding author. 
control for time invariant center-specific effects that affect the rate of living donor kidney transplantation and $\theta_{t}$ are month-year fixed effects that control for any time varying macro effects. We clustered standard errors at the region level, where region is defined by the Organ Procurement Organization territories that serve as the primary basis for the allocation of deceased donor organs. The coefficient of primary interest is $\gamma_{1}$ as it provides a measure of NLDAC's impact on those enrolled in the program.

When estimating this model, as well as the other regressions specified, we investigate the robustness of our estimates to the inclusion and exclusion of the center fixed effects, $\alpha_{i}$, and month-year fixed effects, $\theta_{t}$. To preserve the difference-in-difference identification strategy we include the variable Enrolled $_{i}$ when we remove the center fixed effects, $\alpha_{i}$. Enrolled ${ }_{i}$ takes a value of one for any center that enrolled with NLDAC. This is a time invariant variable which becomes collinear with $\alpha_{i}$ and is therefore removed when we include center fixed effects. When we elect to remove the month-year fixed effects, $\theta_{t}$, we include a variable Post $t_{t}$ that indicates whether or not the data observed is in the post-NLDAC period. When we include $\theta_{t}$ this variable is dropped due to collinearity as the post-NLDAC effects are subsumed in the month-year fixed effects, $\theta_{t}$.

The second specification identifies the impact of NLDAC based on whether or not a center filed with NLDAC rather than just being enrolled in the program. The model includes an interaction term between the indicator variable for whether the center enrolled in NLDAC, NLDAC $C_{i t, \text { enrolled, }}$ with another term that takes a value of one as soon as a center elected to file with NLDAC, $N L D A C_{i t, \text { filed }}$, defined as enrolled and filing at least once in Figure 2. The revised difference-in-difference equation we estimate is,

$$
O_{i t}=\beta_{1} \text { Wait }_{i t}+\beta_{2} C M S_{i t \mid p a t / g r a f t}+\gamma_{1} N L D A C_{i t, \text { enrolled }}
$$


$+\gamma_{2}\left(N L D A C_{i t, \text { enrolled }}\right) \times\left(N L D A C_{i t, \text { filed }}\right)+\delta_{i t} X_{i t}+\alpha_{i}+\theta_{t}+e_{i t}$.

The specification outlined in Equation 2 measures the treatment effect for centers that enrolled in NLDAC and then elected to actively file with NLDAC from the time period of first filing to the end of the data set.

Therefore, the coefficient $\gamma_{2}$ captures the average treatment effect of all centers who ever filed with NLDAC following their first filing. We added another variable, Filed $_{i}$, when the center fixed effects, $\alpha_{i}$, are omitted which indicates whether or not the center is one which enrolled and filed with NLDAC in our data set. This is a time invariant variable that holds across both pre- and post-NLDAC time periods. An alternative specification that exploits the timing of when centers elect to file with NLDAC as well as the fact that some centers elect to file in some years but not others is,

$$
\begin{aligned}
& O_{i t}=\beta_{1} \text { Wait }_{i t}+\beta_{2} C M S_{i t \mid p a t / g r a f t}+\gamma_{1} N L D A C_{i t, \text { enrolled }} \\
& +\gamma_{2}\left(N L D A C_{i t, \text { enrolled }}\right) \times\left(N L D A C_{i t, \text { active }}\right)+\delta_{i t} X_{i t}+\alpha_{i}+\theta_{t}+e_{i t} .
\end{aligned}
$$

The difference between Equation 2 and Equation 3 reflects alternative definitions of "participation" in the NLDAC program. The variable $N L D A C_{i t, \text { active }}$ is a binary variable that takes a value of one if the center elected to file with NLDAC in a given year and zero otherwise. Active centers in year $t, N L D A C_{i t, \text { active }}$, are a subset of those that filed an application at any point in the post-NLDAC period, $N L D A C_{i t, f i l e d}$. In this specification the treatment variable, $\gamma_{2}$, captures the treatment effect for centers that enrolled with NLDAC and actively filed a reimbursement claim in a particular year. We also include a variable Active $_{i}$ when we remove the center fixed effects, $\alpha_{i}$, which is a time invariant indicator variable for all centers that enrolled with NLDAC and actively filed with them following the start of the NLDAC program. 
The final specification combines Equation 2 and Equation 3 and mirrors the partitioning of the data illustrated in Figure 5. The model we estimate is,

$$
\begin{aligned}
& O_{i t}=\beta_{1} \text { Wait }_{i t}+\beta_{2} C M S_{i t \mid p a t / g r a f t}+\gamma_{1} N L D A C_{i t, \text { enrolled }}+\gamma_{2}\left(N L D A C_{i t, \text { enrolled }}\right) \times\left(N L D A C_{i t, \text { filed }}\right) \\
& +\gamma_{3}\left(N L D A C_{i t, \text { enrolled }}\right) \times\left(N L D A C_{i t, \text { filed }}\right) \times\left(N L D A C_{i t, \text { active }}\right)+\delta_{i t} X_{i t}+\alpha_{i}+\theta_{t}+e_{i t} .
\end{aligned}
$$

This specification is a quasi-triple difference estimator that uses a the triple interaction term to capture the impact of enrolling in NLDAC and filing a reimbursement claim with NLDAC in a given year. It is not a true triple difference model because we do not incorporate an interaction term between $N L D A C_{i t, \text { filed }}$ and $N L D A C_{i t, a c t i v e}$ nor the interaction term between $N L D A C_{i t, \text { enrolled }}$ and $N L D A C_{i t, \text { active }}$. These interactions are not included because they are identical to the triple interaction term contained in Equation 4 as centers which filed at some point following the creation of NLDAC or actively filed in a given year are by definition enrolled in NLDAC. To preserve the quasi-triple difference specification we incorporate the variables Enrolled ${ }_{i}$ Post $t_{t}$ and Filed $_{i}$ as needed when we removed the center and month-year fixed effects. ${ }^{18}$ The treatment effect captured by $\gamma_{3}$ measures differences in the monthly number of transplants that can be attributed to a center filing an application with NLDAC at a given point in time and is identified using within center variation in the timing of centers' NLDAC filings.

Each of the regression models specified provides information on the NLDAC program. The first

18 We do not utilize the Active $_{i}$ variable because it is the same as Filed $_{i}$. 
specification, Equation 1, investigates the raw enrollment effects which we expect to be large because centers that enrolled in the program conducted a majority of the transplants in both the pre- and post-NLDAC period. Our results from estimating this model are biased upward by the selection effect of these transplant centers enrolling in NLDAC. The second specification, Equation 2, controls for the enrollment bias and estimates an average treatment effect for those centers who filed with NLDAC at any point in time. Given that $N D A C_{i t, \text { filed }}$ takes a value of one as soon as a center elects to file with NLDAC and remains at one regardless of their future filing decisions, our estimates from this model capture the average treatment effect of filing with NLDAC in the post-NLDAC. The estimates from this model represent our purest estimates of the average treatment effects but if there are unobserved center-specific factors that are not controlled for by our center fixed effects or center specific covariates the results may be biased. However, we do believe that these factors are well controlled for in our empirical specification.

Our third and forth specifications, Equations 3 and 4, attempt to purge out any of the unobserved center-specific information by using within transplant center variation in the timing of their filings with NLDAC. This is achieved through the use of the variable $N L D A C_{i t, a c t i v e}$ that takes a value of one only in the years that a center filed for reimbursement with NLDAC. This group is a subset of those that have filed and therefore these estimates attempt to further refine our estimates obtained using Equation 2. In these specifications a center may serve as its own control when they elect to file for a reimbursement with NLDAC in a given year. However, if there are unobserved time specific factors that influence a center's filing decision (i.e., an increased flow of low income donors in a given month) this may bias the results. Comparing the results from Equation 2 with those obtained from Equations 3 and 4 will provide information on this potential bias.

Regardless of the empirical specification utilized the identification strategy employed requires that the pre-NLDAC trends in the data are parallel for our defined treatment and control groups. Given the large amount of data we have during the pre-NLDAC time period this can be empirically tested. To conduct a test of our identification strategy we estimate the following set of models using the data from the pre-NLDAC time period, 
$O_{i t}=\beta_{1}$ Wait $_{i t}+\beta_{2} C M S_{i t \mid p a t / g r a f t}+\gamma_{1}$ Trend $_{t}+\gamma_{2}$ Enrolled $_{i}$

$+\gamma_{3}$ Trend $_{t} \times$ Enrolled $_{i}+\delta_{i t} X_{i t}+\alpha_{i}+\theta_{t}+e_{i t}$

$O_{i t}=\beta_{1}$ Wait $_{i t}+\beta_{2} C M S_{i \mid \text { pat } / g r a f t}+\gamma_{1}$ Trend $_{t}+\gamma_{2}$ Filed $_{i}$

$+\gamma_{3}$ Trend $_{t} \times$ Filed $_{i}+\delta_{i t} X_{i t}+\alpha_{i}+\theta_{t}+e_{i t}$

$O_{i t}=\beta_{1}$ Wait $_{i t}+\beta_{2}$ CMS $_{\text {it|pat } / \text { graft }}+\gamma_{1}$ Trend $_{t}+\gamma_{2}$ Enrolled $_{i}+\gamma_{3}$ Filed $_{i}$

$+\gamma_{4}$ Trend $_{t} \times$ Enrolled $_{i}+\gamma_{5}$ Trend $_{t} \times$ Filed $_{i}+\delta_{i t} X_{i t}+\alpha_{i}+\theta_{t}+e_{i t}$.

The variable Trend $_{t}$ is a time trend variable, Enrolled $_{i}$ and Filed $_{i}$ are variables that indicate whether or not a center was enrolled in the NLDAC, or enrolled and filed with the NLDAC respectively in the post-NLDAC time period. All of the other variables are as defined earlier. In order for our identification strategy to be valid we require that coefficient on $\gamma_{3}$ in Equations 5 and 6 and the coefficient on $\gamma_{5}$ in Equation 7 to be statistically insignificant. The results from these regressions are contained in Table 2 when we use the covariate control $C M S_{i|| g r a f t} .{ }^{19}$ The results in Table 2 support our hypothesis that the pre-NLDAC data trends are parallel across our different treatment and control groups in the analysis and consistent with the graphical representation

19 The results when we use the covariate control $C M S_{i t \mid p a t}$ are qualitatively similar to those when we use the $C M S_{i|| g r a f t}$ variable and can be obtained from the corresponding author.

This article is protected by copyright. All rights reserved. 
of the data trends provided in Figures 3 through 5 . The only statistically significant coefficients arise for the variable Trend $_{t} \times$ Enrolled $_{i}$ when we do not control for either transplant center heterogeneity using the center fixed effects, $\alpha_{i}$, or month-year fixed effects, $\theta_{t} .^{20}$ However, when we control for both fixed effects the coefficients are all consistent with our identification strategy.

Having defended our identification strategy, the results from the four sets of regressions are illustrated in Tables 3 and 4, which are broken down by whether or not the one-year graft or patient survival CMS CoP variables were utilized in the regression model. ${ }^{21}$ In each Table there are four panels that correspond with the different regression specifications utilized. Panel A contains the regression results for Equation 1, Panel B contains the results for Equation 2, Panel C contains the regression results for Equation 3 and Panel D contains the regression results for Equation 4. The different columns in each panel correspond with alternative specifications resulting from including or not including different combinations of the fixed effect variables $\alpha_{i}$ and $\theta_{t}$, which are labeled in each panel of Tables 3 and 4. The coefficients are presented as incident rate ratios and can be interpreted as percent changes in monthly living donor kidney transplants.

${ }^{20}$ When we use center fixed effects, $\alpha_{i}$, the Enrolled $_{i}$ variable is removed from the model and when we use month-year fixed effects, $\theta_{t}$, the Trend ${ }_{i}$ variable is removed for collinearity concerns.

${ }^{21}$ The two measures are collinear and often go hand in hand, however the one-year patient survival CMS CoP occurs slightly less than the 1-year graft survival measure. Due to this close relationship between the two measures we elected to run separate regressions for each CMS CoP versus one regression with both CMS CoP variables. 


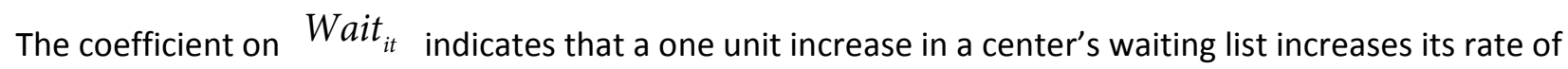
living donor kidney transplantation by between $0.03 \%$ and $0.06 \%$. The stability of the coefficients across Table 3 and 4 suggest that either of the CMS CoPs is sufficient to control for the regulatory pressures that a transplant center faces. In nearly all of the specifications when a center does not meet the CMS CoP they reduce their volume of living donor kidney transplants. ${ }^{22}$ Our preferred specification, which contains center and month-year fixed effects, indicates that there is a large reduction, $13 \%$, in the number of living donor transplants in centers that do not meet the CMS standards.

The incidence rate ratios for our first empirical specification with month-year and center fixed effects indicate that enrolling in NLDAC generated a $22 \%$ increase in the monthly number of living donor organ transplants. Estimates vary widely depending on the specification, ranging from around $14 \%$ when we include only transplant center fixed effects to $78 \%$ when we include only month-year fixed effects. This highlights the importance of controlling for center-level heterogeneity as well as the macro time trends in living donor organ transplantation during this time period. The results from our second specification, Equation 2, illustrate that there is in fact a selection effect associated with enrollment in NLDAC as the coefficient on $N L D A C_{i t, e n r o l l e d}$ is statistically significant and positive when we control for both center and month-year fixed effects. However, the treatment variable of interest, the coefficient on $N L D A C_{i t, \text { enrolled }} \times N L D A C_{i t, \text { filed }}$, indicates that the monthly number of transplants increased for centers that enrolled with NLDAC and had filed at least once with them in the

${ }^{22}$ The primary exception to this arises in the 1-year patient survival rate models when we do not include the center-level fixed effects, $\alpha_{i}$. However, the CMS effects are robust across all of our most preferred specifications that include both the center-level and month-year fixed effects. 
post-NLDAC period. This increase ranges from approximately $11 \%$ to $46 \%$ depending on the specification. Our preferred specification, the one that controls for both center fixed and month-year fixed effects, indicates that the monthly number of living donor transplants increased by approximately $14 \%$ among those centers that enrolled in NLDAC and subsequently filed a request for cost assistance. This represents the average treatment effect of enrolling in NLDAC and filing at least once for cost assistance in the post-NLDAC time period.

As mentioned earlier, our second specification, Equation 2, does not use information on the timing of a center's filing following their first filing with NLDAC. The specification outlined in Equation 3 does address the timing of a center's filings following their first filing with NLDAC. The treatment variable of interest, the coefficient on $N L D A C_{i t, \text { enrolled }} \times N L D A C_{i t, \text { active, }}$ indicates that the monthly number of living donor organ transplants increased by almost $15 \%$ when a center enrolled in NLDAC and actively filed with NLDAC in a given year. Again, these values vary substantially depending on whether or not we include center or month-year fixed effects and in the case of the 1-year patient survival model are actually statistically insignificant when we do not include center fixed effects.

In the fourth specification each participating center may serves as its own control. ${ }^{23}$ The model includes the following interaction terms; $N L D A C_{i t, \text { enrolled }} \times N L D A C_{i t, \text { filed }}$ and $N L D A C_{i t, \text { enrolled }} \times N L D A C_{i t, \text { filed }} \times N L D A C_{i t, \text { active }}$. By construction our treatment variable captures the impact of NLDAC on a center that has enrolled in the program, has already filed with NLDAC at some point in time and actively filed in the current year versus the same center when it was not actively filing with NLDAC in a given year. As mentioned earlier, this specification may be biased if their are unobserved time specific factors that determine

${ }^{23} 54 \%$ of centers that filed with NLDAC actively filed in each year following their initial filing. 
when a center elects to file. However, the decision to file in a given year depends on the pool of patients who seek treatment in that time period and the availability of living organ donors for those patients. The centers do not have control over these factors so for the most part these are exogenous factors.

The treatment effect for our fourth specification, Equation 4, ranges from approximately $84 \%$ to $14 \%$ depending on the model specification. The largest treatment effects are observed when we do not utilize transplant center fixed effects. As was the case with the other specifications this highlights the importance of controlling for center level heterogeneity. Focusing on the specification that controls for both center level heterogeneity and month-year time trends we can see that the treatment effect is remarkable stable. The parameter estimate for the 1-year graft survival model indicates an increase in living donor transplants of $14.37 \%$ and the 1-year patient survival model results generate an increase of $13.79 \%$; the average is $14.08 \%$.

The estimates for our second through fourth specification, Equations 2 through 4, are all remarkably stable and similar. The estimates from our preferred specification, that which controls for center and month year fixed effects, indicate that treatment effect varies between $13.49 \%$ and $14.37 \%$ for the 1 -year graft survival CMS CoP models and between $13.79 \%$ and $14.72 \%$ for the 1-year patient survival CMS CoP models. Although each of these models possesses inherent strengths and weaknesses the results allow us to comfortably state that filing for cost reimbursement with NLDAC increased the monthly rate of living organ transplantation by approximately $14 \%$. Furthermore, the confidence intervals for each of these different treatment effects overlaps one another, further highlighting the consistency of our results.

Our most conservative estimate of the impact that the NLDAC had on the number of living donor kidney transplants indicates that it increased them by $13.5 \%$ (SE 7.1\%). The estimates come from our second specification and the 1-year graft survival CMS CoP model when we control for transplant center and month-year fixed effects. Transplant centers enrolled and participating in NLDAC performed an average of 29 living donor kidney 
transplants per year. There were 136 centers that we observed filing with NLDAC for living donor assistance in the final year of our analysis, 2012. We estimate that NLDAC increased the number of living donor kidney transplants by approximately 532 [95\% Cl: $16-1115]$ procedures annually $(=0.135 * 29 * 136) .{ }^{24}$ The actual number of living donor kidney transplants supported by NLDAC in 2012, the last year of our analysis, was 426 . Our empirical results suggest that none of these transplants would have happened without the support of NLDAC (532 > 426).

However, there is a wide confidence interval around the point estimate, so we do not have a high degree of confidence in this conclusion. This result is consistent with the post-transplantation surveys conducted by NLDAC that indicate nearly three-quarters of the kidney transplants would not have taken place if the compensation was not provided (Mathur et al. 2014).

Matas and Schnitzler (2004) calculate that a living donor kidney transplant (versus dialysis) reduces health care costs by $\$ 94,579$ (US dollars, 2002) and results in a gain of 3.5 quality-adjusted life years (QALY). Inflating cost savings to 2013 dollars using the all-time consumer price index and valuing a QALY at $\$ 100,000$, a living donor kidney transplant is associated with a net gain to society of $\$ 473,000$. This figure and the results presented in the previous paragraph imply that NLDAC was associated with a benefit of $\$ 252$ million [95\% Cl: \$8 million-\$527 million] (evaluated in 2013 dollars). This figure far exceeds the approximately $\$ 1.8$ million that NLDAC recently spent on donor aid. ${ }^{25}$

24 The confidence intervals for our other estimates are tighter.

${ }^{25}$ An alternative calculation of the benefits would utilize the value of statistical life that ranges between $\$ 4$ and $\$ 10$ million (Kneisner et al. 2012). However, using this estimate requires some heroic assumptions regarding the outcome of a patient if they did not receive a living organ transplant at a particular point in time. Therefore, we have elected to utilize the more conservative estimates of the benefits derived by Matas and Schnitzler (2004) 
All of the estimates discussed do not account for any form of temporal decay in the treatment or anticipatory efforts made by the transplant centers. If centers increased their rates of living organ transplantation prior to their enrollment in NLDAC, indicating an anticipatory effort, it would bias our parameter estimates downward as well as violate our fundamental assumption that the NLDAC program is exogenous. Temporal treatment decay is important to investigate to determine whether or not the treatment effects we observe continue beyond the inception of the NLDAC or were they transitory and perhaps the result of an immediate clearing out of potential donors that perviously were unable to be a living organ donor. To investigate this in more detail we re-estimated Equation 1 and Equation 2 with time varying treatment coefficients. The time varying treatment coefficients contain a twelve month pre- and post- treatment variable lag as well as a parameter for the first month of the treatment and another for all periods of time beyond the twelfth month of initial treatment. The results from these estimations are contained in Figure 6 with 90\% confidence intervals. ${ }^{26}$

The parameter estimates in Figure 6 indicate that all of the pre-treatment coefficients are not statistically significant from one, suggesting that centers did not increase transplant volumes in anticipation of the NLDAC program. The treatment effects from our modified Equation 1 are all statistically significant and higher than an incidence rate of one. Furthermore, the treatment effect is stable across the post-treatment time period. The estimates for Equation 2 are very similar to those observed for Equation 1 in the pretreatment period and there does not appear to be any statistically significant anticipatory effects observed among centers that enrolled in NLDAC and then elected to file their first claim with NLDAC. The post-NLDAC treatment variables do not indicate

that focus on the QALYs generated following transplantation.

${ }^{26}$ It is not possible to estimate pre- and post-treatment variables for Equations 3 and 4 because the $N L D A C_{i t, a c t i v e}$ variable is a subset of the $N L D A C_{i t, \text { filed }}$ variable used to define the timing of our treatment variable. 
as strong of a treatment effect as observed with the re-estimation of Equation 1 as only a little over half of the treatment parameters are significantly different from an incidence rate of one. This said, the upward trajectory in the point estimates is consistent with that observed in our re-estimation of Equation 1.

Given the impact that the inclusion of transplant center fixed effects has on our estimates, we decided to investigate where the primary treatment effects arise within the distribution of kidney transplant centers. We calculated the average number of living donor kidney transplants conducted for each center during our time period of analysis and ranked them from highest to lowest. We then created dummy variables for each quartile and interacted these dummy variable with the treatment and control variables used in the model to determine whether or not the treatment effect is heterogeneous across the distribution of transplant centers using the same Poisson regression framework outlined earlier. The results from this specification are contained in Tables 5 and 6 for the two CMS CoPs respectively.

Focusing on the treatment variables illustrated in Tables 5 and 6 we see that the NLDAC program has had no impact on those centers in the highest quartile of the living donor kidney transplantation activity. Our first parameterization, Equation 1, illustrates that we observe a treatment effect for only the lowest quartile of the distribution where we observe an increase in living donor organ transplants of approximately $93 \%$. Our estimates for our second parameterization, Equation 2, indicate that the NLDAC program increased living donor organ transplants for the second and fourth quartile by approximately $12 \%$ and $57 \%$ respectively. ${ }^{27}$ Our third specification, Equation 3, generates the broadest spread in the treatment effect as all of the quartiles possess a treatment effect except the highest quartile. The treatment effects are lowest for the second highest quartile, $17 \%$, and highest for the lowest quartile, $55-56 \%$, with the third quartile possessing a treatment effect of approximately $26-27 \%$. The last specification, corresponding to the redefined Equation 4 , generates a treatment

27 The $57 \%$ is an average across the two CMS CoP criteria. 
effect for only the lower two quartiles. The second lowest quartile possesses a treatment effect between $40-42 \%$ whereas the lowest quartile possesses a treatment effect of $36-37 \%$.

These results indicate that the impact of the NLDAC was minimal at the upper tail of the distribution but sizable at the lower tail of the activity distribution. One possible explanation is that those centers at the upper tail of the distribution are already conducting a sufficiently large number of living donor kidney transplants and their pool of potential donors is sufficient to meet their current demands. Alternatively, such centers may have reached internal resource limits that constrain further increases in the number of living donor kidney transplants. On the opposite end of the spectrum is the lower tail of the distribution where they may not have a sufficient supply of living organ donors and the program has allowed them to utilize a previously unusable pool of potential donors. A more rigorous investigation of the cause of this heterogeneity is beyond the scope of this research effort, but it is clear that the treatment effect of NLDAC is not homogeneous and concentrated more at the lower tail of the living donor kidney transplant distribution.

\section{Falsification Tests}

We conduct two separate falsification tests to validate the estimated impact of the NLDAC program on living donor kidney transplantation. The first tests the effect of the NLDAC program on deceased donor kidney transplants. The NLDAC program did not directly target deceased donor kidney transplantation so we would expect that the NLDAC program would either have had no effect on deceased donor kidney transplantation or it may have a negative effect because there is a substitution effect between living and deceased donor kidney transplants (Howard 2011, Fernandez et al. 2013). Table 7 illustrates our falsification test results using deceased donor kidney transplantation. In this table we reproduce our preferred specification contained in Tables 3 and 4 for each of the four models and juxtapose those estimates with the estimated treatment that the NLDAC program had on the exact same center's monthly levels of deceased donor kidney transplants. For all of the specifications estimated we find that the NLDAC program had no statistically significant impact on the monthly number of deceased donor kidney transplants conducted by the same centers investigated in our research. Although the parameter estimates are not statistically significant it is interesting to note that our fourth specification, Equation 
4, generates a small and statistically insignificant negative effect (incidence rate is below one, but not statistically significant). ${ }^{28}$

The second falsification test we conduct investigates the effect of the NLDAC program on the monthly number of thoracic transplants (heart, lung, and heart-lung transplants combined). Hearts and lungs are obtained from deceased donors only, and so we would not expect the NLDAC program to have an impact on their volume. During the time period studied there were 129 transplant centers that conducted non-pediatric thoracic transplants and there are 119 centers that conducted both non-pediatric thoracic transplants and living donor kidney transplants. For each of these samples we estimated the empirical models and compared the treatment effects. We did not include a control for the number of patients waiting for a kidney transplant or the waiting list control variables, $X_{i t}$, in the thoracic transplant regression set up as the kidney waiting list is not applicable to this population. Furthermore, waiting for a thoracic transplant for an extended period of time is not feasible, given the lack of substitutes for a thoracic transplant, whereas with kidney transplantation a patient can be treated with dialysis and continue waiting for an organ.

The regression results are contained in Table 8 and they further validate the estimated relationship between the NLDAC program and living donor kidney transplantation. The table presents results for the living donor kidney transplant center volume juxtaposed with the results for thoracic transplant volume to facilitate comparison. The results for the living donor kidney transplant center volume are similar to those illustrated in Tables 3 and 4, except for the fact that we limit these regressions to only those 119 centers that conducted both kidney and thoracic transplants. Including the full sample of living donor kidney centers would potentially bias the

28 The combination of the living and deceased donor transplant results indicate that the overall number of transplants conducted increased following the NLDAC. 
results in favor of our falsification test. The restricted sample was used to illustrate that the NLDAC program still had a positive impact on the center's volume of living donor kidney transplants for those that did both thoracic and living donor kidney transplants.

In all of our specifications the treatment effect for thoracic transplants was statistically insignificant. This indicates that NLDAC program has had no impact on the rate of thoracic transplants conducted by the 129 transplant centers that conducted thoracic transplants during our time period of study. The treatment effects on living donor kidney transplants for the 119 centers that conducted both living donor kidney and thoracic transplants is statistically significant for the specifications illustrated in Equation 3 and Equation 4. The treatment effect it is not statistically significant for the specification illustrated in Equation 1 and Equation 2, however the sign is as expected for Equation 2. The treatment effects for our estimation of Equation 3 are approximately 15\% for both of the CMS CoP specifications and the treatment effect for Equation 4 is $22 \%$ for the graft survival CMS CoP and $21 \%$ for the patient survival CMS CoP.

The combination of these results clearly supports our hypothesis that the NLDAC is associated with a sizable increase in living donor kidney transplantation. Our initial treatment effect for the complete sample is approximately $14 \%$. This estimate is consistent with the treatment effect observed among the 119 transplant centers that conducted both living donor kidney and thoracic transplants. Finally, the lack of a treatment effect on thoracic transplants for the 129 centers that conducted thoracic transplants validates the treatment effects observed in our complete sample.

\section{Conclusion}

We find that the NLDAC program increased the monthly number of living donor kidney transplants by approximately $14 \%$ for those centers that enrolled and actively participated. These findings contribute to the growing literature on the impact that programs targeted at reducing donor out-of-pocket costs have had on organ donation (Boulware et al. 2008; Lacetera et al. 2014; Venkataramani et al. 2012; Wellington and Sayre 2011). Contrary to these earlier papers, we find that the NLDAC offset donor costs enough to have a positive effect on 
donor behavior. Conventional estimates of the aggregate annual welfare gains from NLDAC exceed \$220 million. ${ }^{29}$

Our results imply that in the pre-NLDAC period some potential donors did not donate because of the costs associated with travel. If a living donor kidney transplant is associated with such substantial health benefits-benefits that exceed average travel costs $(\$ 2,800)$ at least by a factor of 25 if not much more-why weren't donors and recipients willing to incur these costs? The fact that they were not suggests some combination of 1) altruism for some donors on the margin is low, 2) some recipients believe, incorrectly, it is illegal for them to pay their donor's travel expenses, or 3) many donors and recipients face severe credit constraints. Regardless, the results from our analysis clearly indicate that the NLDAC program provided a sufficient amelioration of the financial disincentives to support the altruistic motives of the donors. The financial benefits of the program to the health care system have far exceeded the costs.

Our findings indicate that programs used to offset some of the costs that donors incur in the process of donation increase living donation rates. The success of NLDAC does not imply that the U.S. should adopt a full-scale market for organs. Under such a market, donors would have positive net benefits and the donor pool would include donors who donate solely for financial gain as well as for altruistic motivates. If the extrinsic benefits from donating are sufficiently large, it is possible that incentives could crowd-out prosocial, intrinsically-motivated behavior (Bènabou and Tirole 2006). In the context of living kidney donation, as the number of financially-motivated donors increases, the altruistically-minded individuals who are the target of NLDAC assistance may begin to drop-out of the donor pool.

The experience of NLDAC shows that it is possible to use financial incentives without violating NOTA's "valuable consideration" clause or risking crowd-out of intrinsic motivation. Gaston et al. (2006) proposed a more

29 This statistic is based on NLDAC activity in 2012 and varies depending on year. 
ambitious program that would provide a one-year term life insurance policy for living donors, health insurance to cover their future risks, the reimbursement of a broader set of donor related expenses and either a tax deduction of $\$ 10,000$ or a direct payment of $\$ 5,000$, perhaps our results can be used to support piloting this program at a small scale to investigate its efficacy. Our results suggest that potential living organ donors are sensitive to the costs of donating and programs to make donors whole by compensating them for the actual and expected costs associated with donating could increase donation rates. Given the potential gains from increasing the number of living donors, the government may want to consider conducting a pilot program that provides benefits above and beyond the limited compensation offered by NLDAC.

\section{References}

Abadie, A. and S. Gay. 2006. The Impact of Presumed Consent Legislation on Cadaveric Organ Donation: A Cross-Country Study. Journal of Health Economics 25: 599-620.

Abecassis, M.M., Burke, R., Cosimi, A.B., Matas, A.J., Merion, R.M., Milman, D., Roberts, J.P. and G.B. Klintmalm. 2008. Transplant Center Regulations - A Mixed Blessing? An ASTS Council Viewpoint. American Journal of Transplantation 8: 2496-2502.

Adams, A.F., Barnett, A.H. and D.L. Kaserman. 1999. Markets for Organs: The Question of Supply. Contemporary Economic Policy 17(2): 147-155.

Andreoni, J. 1990. Impure Altruism and Donations to Public Goods: A Theory of Warm Glow Giving. The Economic Journal 100: 464-487.

Beard, T.R., Kaserman, D.L. and R.P. Saba. 2004. Limits to Altruism: Organ Supply and Educational Expenditures. Contemporary Economic Policy 22(4): 433-441.

Becker, G.S. and J.J. Elias. 2007. Introducing Incentives in the Market for Live and Cadaveric Organ Donations. Journal of Economic Perspectives 21(3): 3-24.

This article is protected by copyright. All rights reserved. 
Bénabou, R. and J. Tirole. 2006. Incentives and Prosocial Behavior. American Economic Review 96(5): 1652-78.

Boulware, L.E., Troll, M.U., Wang, N.Y. and N.R. Powe. 2006. Public Attitudes Toward Incentives for Organ Donation: A National Study of Different Racial/Ethnic and Income Groups. American Journal of Transplantation 6: 2774-2785.

Boulware, L.E., Troll, M.U., Plantinga, L.C. and N.R. Powe. 2008. The Association of State and National Legislation with Living Kidney Donation Rates in the United States: A National Study. American Journal of Transplantation 8: 1451-1470.

Byrne, M.M. and P. Thompson. 2001. A Positive Analysis of Financial Incentives for Cadaveric Organ Donation. Journal of Health Economics 20: 69-83.

Cohen, L.R. 1989. Increasing the Supply of Transplant Organs: The Virtues of a Future Market. George Washington Law Review 58(1): 1-51.

Cox, J.C., Sadiraj, V., Schnier, K.E. and N. Turgeon. 2012. Loss Aversion and Organ Utilization. Working Paper, Department of Economics, Georgia State University.

Delmonico, F.L., Arnold, R., Scheper-Hughes, N., Siminoff, L.A., Kahn, J. and S.J. Younger. 2002. Ethical Incentives Not Payment - for Organ Donation. New England Journal of Medicine 346(25): 2002-2005.

Dickinson, D.M., Arrington, C.J., Fant, G., Levine, N., Schaubel, D.E., Pruett, T.L., Roberts, M.S. and R.A. Wolfe. 2008. SRTR Program-Specific Reports on Outcomes: A Guide for the New Reader. American Journal of Transplantation 8: 1012-26.

Dickinson, D.M., Shearon, T.H., O’keefe, J.O., Wong, H.H., Berg, C.L., Rosendale, J.D., Delmonico, F.L., Webb, R.L. and R.A. Wolfe. 2006. SRTR Center-Specific Reporting Tools: Posttransplant Outcomes. American Journal of Transplantation 6: 1198-1211.

This article is protected by copyright. All rights reserved. 
Dikert-Conlin, S., Elder, T. and B. Moore. 2011. Donorcycles: Motorcycle Helmet Laws and the Supply of Organ Donors. Journal of Law and Economics 54(4): 907-35.

Danovitch, G.M. and A.B. Leichtman. 2006. Kidney Vending: The "Trojan Horse" of Organ Transplantation. Clinical Journal of the American Society of Nephrology 1: 1133-1135.

Delmonico, F.L., Martin, D., Dominquez-Gil, B., Muller, E., Jha, V., Levin, A., Danovitch, G.M. and A.M. Capron. 2015. Living and Deceased Organ Donation Should Be Financially Neutral Acts. American Journal of Transplantation 15(5): 1187-91.

Epstein, R.A. 2008. The Human and Economic Dimensions of Altruism: The Case of Organ Transplantation. Journal of Legal Studies 37(2): 459-501.

Ferguson, E. 2013. Defining and Measuring Blood Donor Altruism: A Theoretical Approach from Biology, Economics and Psychology. Vox Sanguinis 106: 118-126.

Ferguson, E. 2015. Mechanism of Altruism Approach to Blood Donor Recruitment and Retention: A Review and Future Directions. Transfusion Medicine 25: 211-226.

Fisher, J.S., Butt, Z., Friedewald, J., Fry-Revere, S., Hanneman, J., Henderson, M.L., Ladin, K., Mysel, H., Preczewski, L., Sherman, L.A., Thiessen, C. and E.J. Gordon. 2015. Between Scylla and Charybdis: Charting an Ethical Course for Research Into Financial Incentives for Living Kidney Donation. American Journal of Transplantation 15(5): 1180-86.

Fernandez, J.M., Howard, D.H. and L.S. Kroese. 2013. The Effect of Cadaveric Kidney Donations on Living Kidney Donations: An Instrumental Variables Approach. Economic Inquiry 51(3): 1696-1714.

Fox, M.D. 2006. The Price is Wrong: The Moral Cost of Living Donor Inducements. American Journal of Transplantation 6: 2529-2530.

This article is protected by copyright. All rights reserved. 
Gaston, R.S., Danovitch, G.M., Epstein, R.A., Kahn, J.P., Matas, A.J. and M.A. Schnitzler. 2006. Limiting Financial Disincentives in Live Organ Donation: A Rational Solution to the Kidney Shortage. American Journal of Transplantation 6: 2548-2555.

Howard, D.H. 2007. Producing Organ Donors. Journal of Economic Perspectives 21(3): 25-36.

Howard, D.H. 2011. Waiting Time as a Price for Deceased Donor Kidneys. Contemporary Economic Policy 29(3): 295-303.

Howard, R.J. 2007. Missed Opportunities: The Institute of Medicine Report: Organ Donation: Opportunities for Action. American Journal of Transplantation 7: 14-16.

Imbens, G.W. and D.R. Rubin. 2015. Causal Inference for Statistics, Social and Biomedical Sciences: An Introduction. Cambridge University Press, Cambridge and New York.

Imbens, G.W. and J.M. Wooldridge. 2009. Recent Advancements in the Econometrics of Program Evaluation. Journal of Economic Literature 47(1): 5-86.

Israni, A.K., Halpern, S.D., Zink, S., Sidhwani, S.A. and A. Caplan. 2005. Incentive Models to Increase Living Kidney Donation: Encouraging Without Coercion. American Journal of Transplantation 5: 15-20.

Kaserman, D.L. and A. H. Barnett. 2002. The U.S. Organ Procurement System: A Prescription for Reform. The AEI Press, Washington D.C.

Kessler, J.B. and A.E. Roth. 2012. Organ Allocation Policy and the Decision to Donate. American Economic Review 102(5): 2018-47.

Kessler, J.B. and A.E. Roth. 2013. Organ Donation Loopholes Undermine Warm Glow Giving: An Experiment Motivated by Priority Loopholes in Israel. Working Paper, Business Economics and Public Policy Department, The Wharton School, University of Pennsylvania.

This article is protected by copyright. All rights reserved. 
Kneisner, T.J., Viscusi, K., Woock, C. and J.P. Ziliak. 2012. The Value of Statistical Life: Evidence from Panel Data. Review of Economics and Statistics 94(1): 74-87.

Lacetera, N. and M. Macis. 2010. Do All Material Incentives for Pro-social Activities Backfire? The Response to Cash and Non-cash Incentives for Blood Donations. Journal of Economic Psychology 31: 738-748.

Lacetera, N. and M. Macis. 2013. Time for Blood: The Effect of Paid Leave Legislation on Altruistic Behavior. Journal of Law, Economics and Organization 29(6): 1384-1420.

Lacetera, N., Macis, M. and R. Slonim. 2012. Will There be Blood? Incentives and Displacement Effects in Pro-Social Behavior. American Economic Journal: Economic Policy 4(1): 186-223.

Lacetera, N., Macis, M. and R. Slonim. 2013. Economic Rewards to Motivate Blood Donations. Science 340: 927-928.

Lacetera, N., Macis, M. and S.S. Stith. 2014. Removing Financial Barriers to Organ and Bone Marrow Donation: The Effect of Leave and Tax Legislation in the U.S. Journal of Health Economics 33: 43-56.

Lavee, J. and D.W. Brock. 2012. Prioritizing registered donors in organ allocation: an ethical appraisal of the Israeli organ transplant law. Current Opinion in Critical Care 18(6): 707-11.

Li, D., Hawley, Z., and K.E. Schnier. 2013. Increasing Organ Donation via Changes in the Default Choice or Allocation Rule. Journal of Health Economics 32(6): 1117-1129.

Manning, W.G., Newhouse, J.P., Duan, N., Keeler, E.B. and A. Leibowitz. 1987. Health Insurance and the Demand for Medical Care: Evidence from a Randomized Experiment. American Economic Review 77(3): 251-277.

Matas, A.J. and M. Schnitzler. 2004. Payment for Living Donor (Vendor) Kidneys: A Cost-Effective Analysis. American Journal of Transplantation 4(2): 216-221.

Mathur, A., Warren, P., Hong, B., Ojo, A. and R.M. Merion. 2014. Return on Investment of Financial Assistance for 
Living Donors: Analysis of 3639 National Living Donor Assistance Center Program Participants. American Journal of Transplantation 14(Suppl 2): 68.

McCune, T.R., Armata, T., Mendez-Picon, G., Yium, J., Zabari, G.B., Crandall, B., Spicer,H.G., Blanton, J. and L.R. Thacker. 2004. The Living Organ Donor Network: A Model Registry for Living Kidney Donors. Clinical Transplantation 18 Suppl. 12: 33-38.

National Kidney Foundation. 2013. Donor Leave Laws and Tax Deductions/Credits for Living Donors 7/26/2013. http://www.kidney.org/transplantation/livingdonors/pdf/LDTaxDed_Leave.pdf

National Kidney and Urological Diseases Information Clearing House (NKUDIC). 2014. Information accessed on the web, last accessed on February 9, 2014. http://kidney.niddk.nih.gov/kudiseases/pubs/kustats/

Organ Procurement and Transplantation Network (OPTN) 2014. Information access on the web, last accessed on March 4, 2014. http://optn.transplant.hrsa.gov/

Ouayogode, M. 2013. Unintended Effects of the CMS Final Rule on Transplantation: A Patient Welfare Question. Working Paper, Department of Economics, Georgia State University.

Pellegrino, E.D. 1991. Families? Self-Interest and the Cadaver's Organs: What Price Consent? Journal of the American Medical Association 265(10): 1305-1306.

Peters, T.G. 1991. Life or Death: The Issue of Payment in Cadaveric Organ Donation. Journal of the American Medical Association 265(10): 1302-1305.

Ross, L.F., Rubin, D.T., Siegler, M., Josephson, M.A., Thistlethwaite, J.R. and E.S. Woodle. 1997. Ethics of a Paired-Kidney-Exchange Program. New England Journal of Medicine 336(4): 1752-1755.

Roth, A.E., Sönmez, T. and M.U. Ünver. 2004. Kidney Exchange. Quarterly Journal of Economics 119(2): 457-488.

Roth, A.E., Sönmez, T. and M.U. Ünver. 2005. A Kidney Exchange Clearinghouse in New England. American

This article is protected by copyright. All rights reserved. 
Economic Review, Papers and Proceedings 95(2): 376-380.

Roth, A.E., Sönmez, T. and M.U. Ünver. 2007. Efficient Kidney Exchange: Coincidence of Wants in Markets with Compatibility-Based Preferences. American Economic Review, Papers and Proceedings 97(3): 828-851.

Roth, A.E. 2007. Repugnance as a Constraint on Markets. Journal of Economic Perspectives 21(3): 37-58.

Rothman, D.J. 2002. Ethical and Social Consequences of Selling a Kidney. Journal of the American Medical Association 288(13): 1640-1641.

Rothman, S.M. and D.J. Rothman. 2006. The Hidden Cost of Organ Sale. American Journal of Transplantation 6: 1524-1528.

Schnier, K.E., Cox, J.C., McIntrye, C., Ruhil, R., Sadiraj, V. and N. Turgeon. 2013a. Transplantation at the Nexus of Behavioral Economics and Healthcare Delivery. American Journal of Transplantation 13: 31-35.

Schnier, K.E., McIntyre, C, Ruhil, R., Sadiraj, V., Cox, J.C., Ouayogode, M.H., Kirk, A.D., Pearson, T.C. and N. Turgeon. 2013b. The Association Between CMS CoP Review Criteria and Deceased Donor Kidney Transplant Waiting Times. Working Paper, Department of Economics, Georgia State University.

Shover L.R., Streem S.B., Boparai N., Duriak, K. and A.C. Novick. 1997. The Psychosocial Impact of Donating a Kidney: Long-term Follow-up From a Urology Based Center. Journal of Urology 156:1596-1601.

Steinbrook, R. 2005. Public Solicitation of Organ Donors. New England Journal of Medicine 353(3): 441-444.

Thorne, E.D. 1996. The Cost of Procuring Market-Inalienable Human Organs. Journal of Regulatory Economics 10: 191-200.

U.S. Renal Data System (USRDS). 2013. Annual Data Report: Atlas of Chronic Kidney Disease and End-Stage Renal Disease in the United States. National Institutes of Health, National Institute of Diabetes and Digestive and Kidney Disease. Bethesda, MD.

This article is protected by copyright. All rights reserved. 
Venkataramani, A.S., Martin, E.G., Vijayan, A. and J.R. Wellen. 2012. The Impact of Tax Policies on Living Organ Donations in the United States. American Journal of Transplantation 12: 2133-2140.

Wellington, A.J. and J.B. Whitmire. 2007. Kidney Transplants and the Shortage of Donors: Is a Market the Answer? Contemporary Economic Policy 25(2): 131-145.

Wellington, A.J. and E.A. Sayre. 2011. An Evaluation of Financial Incentive Policies for Organ Donation in the United States. Contemporary Economic Policy 29(1): 1-13.

\section{Tables and Figures}

Table 1: Descriptive Statistics. The treated group represents those centers that enrolled in NLDAC and filed for assistance at least once in the post-NLDAC period. The untreated group contains all centers that enrolled in NLDAC and never filed in the post-NLDAC period as well as those that never enrolled. All observations are based on monthly time intervals and \% variables are calculated as a percentage of the center's waiting list. The variables are defined as: Monthly Transplants - monthly number of living donor kidney transplants; Waiting List - patients on a transplant center's waiting list; \% Prev. TX - previously received a kidney transplant; \% Male - percentage male; Mean BMI - the average BMI for patients on the waiting list; \% Work Income - percentage employed; \% Higher Educ. - percentage with higher education (at least some college education); \% Func. Stat 1 - does not require physical assistance; \% Func. Stat 2. - requires minimal physical assistance; \% Other Func. Stat - other functional status; \% Public Pay - receiving public funding (i.e., Medicare) for their transplant; \% COPD - chronic obstructive pulmonary disease; \% Exh. Perit. Vasc. - exhausted peritoneal access; \% Prev. Malig. - previous malignancy; \% White - white ethnicity; \% Black - black ethnicity; \% Asian - asian ethnicity; \% Other Ethn. - other ethnicity; \% Type 1 Diab. - type one diabetes; \% Type 2 Diab. - type two diabetes; \%HBV Core - Hepatitis B core antibody; \% HBV Sur. Ant. - Hepatitis B surface antigen; \%HCV Sero. - Hepatitis C positive; \% VAD - some form of

life support; \% Expanded Donor - On expanded donor list; \%Hypertension - hypertension; \%PRA > 80 - percentage of the waiting list with a PRA greater than $80 \%{ }^{*}$ indicates that the normalized differences exceed the 0.25 threshold proposed by Imbens and Rubin (2015). 
Pre-NLDAC

Variable

Monthly

Transplants

Waiting List

332.229

(396.151)

\% Prev. TX

0.068

(0.050)

$\%$ Male

0.577

(0.052)

Mean BMI

26.809

(0.789)

0.065

(0.067)

\% Higher Educ.

0.763

(1.231)

110.682

(183.979)

0.047

(0.184)

25.906

\% Work Income

0.034

(0.057)

0.276
Untreated Norm. Diff.

Treated

2.564

0.534

$0.637^{*}$

0.619 *

(3.000)

(1.090)

$0.570^{*}$

454.542

129.365

$0.575 *$

(546.966)

(143.544)

$0.265^{*}$

0.035

0.029

0.110

(0.029)

(0.051)

$-0.138$

0.584

0.646

$-0.324^{*}$

(0.051)

(0.184)

$0.322 *$

26.807

26.223

$0.357^{*}$

(0.859)

(1.395)

$0.354 *$

0.095

0.051

$0.451 *$

(0.068) (0.070)

$0.335^{*}$

0.408

0.313

$0.378^{*}$ 


\begin{tabular}{|c|c|c|c|c|c|c|}
\hline & $(0.136)$ & $(0.183)$ & & $(0.128)$ & $(0.216)$ & \\
\hline \multirow[t]{2}{*}{ \% Func. Stat. 1} & 0.776 & 0.808 & -0.111 & 0.613 & 0.629 & -0.046 \\
\hline & $(0.203)$ & $(0.204)$ & & $(0.237)$ & $(0.258)$ & \\
\hline \multirow[t]{2}{*}{ \% Func Stat. 2} & 0.107 & 0.105 & 0.009 & 0.196 & 0.150 & 0.169 \\
\hline & $(0.146)$ & $(0.165)$ & & $(0.203)$ & (0.189) & \\
\hline \multirow{2}{*}{$\begin{array}{c}\text { \% Other Func. } \\
\text { Stat. }\end{array}$} & 0.117 & 0.080 & 0.178 & 0.190 & 0.220 & -0.087 \\
\hline & $(0.163)$ & $(0.129)$ & & $(0.228)$ & (0.259) & \\
\hline \multirow[t]{2}{*}{ \% Public Pay. } & 0.276 & 0.396 & $-0.352 *$ & 0.558 & 0.645 & $-0.313^{*}$ \\
\hline & (0.187) & $(0.286)$ & & $(0.135)$ & (0.244) & \\
\hline \multirow[t]{2}{*}{$\%$ COPD } & 0.011 & 0.012 & -0.023 & 0.014 & 0.017 & -0.017 \\
\hline & $(0.016)$ & $(0.041)$ & & $(0.174)$ & (0.029) & \\
\hline \multirow[t]{2}{*}{ \% Exh. Perit. Vasc. } & 0.049 & 0.038 & 0.147 & 0.052 & 0.043 & 0.112 \\
\hline & (0.051) & $(0.055)$ & & $(0.055)$ & (0.059) & \\
\hline \multirow[t]{2}{*}{ \% Prev. Malig. } & 0.034 & 0.040 & -0.061 & 0.050 & 0.072 & -0.140 \\
\hline & (0.025) & (0.095) & & $(0.033)$ & (0.154) & \\
\hline
\end{tabular}

This article is protected by copyright. All rights reserved. 


\begin{tabular}{|c|c|c|c|c|c|c|}
\hline \multirow[t]{2}{*}{$\%$ White } & 0.474 & 0.415 & 0.175 & 0.459 & 0.432 & 0.078 \\
\hline & $(0.216)$ & $(0.253)$ & & $(0.221)$ & $(0.274)$ & \\
\hline \multirow[t]{2}{*}{$\%$ Black } & 0.324 & 0.320 & 0.012 & 0.316 & 0.315 & 0.004 \\
\hline & $(0.217)$ & $(0.241)$ & & $(0.210)$ & (0.249) & \\
\hline \multirow[t]{2}{*}{$\%$ Asian } & 0.127 & 0.168 & -0.155 & 0.148 & 0.174 & -0.086 \\
\hline & $(0.166)$ & $(0.205)$ & & $(0.192)$ & $(0.242)$ & \\
\hline \multirow[t]{2}{*}{ \% Other Ethn. } & 0.075 & 0.090 & -0.082 & 0.076 & 0.079 & -0.017 \\
\hline & (0.099) & (0.154) & & $(0.095)$ & $(0.150)$ & \\
\hline \multirow[t]{2}{*}{ \% Type 1 Diab. } & 0.035 & 0.022 & 0.148 & 0.063 & 0.049 & 0.246 \\
\hline & $(0.042)$ & $(0.034)$ & & $(0.044)$ & $(0.081)$ & \\
\hline \multirow[t]{2}{*}{ \% Type 2 Diab. } & 0.101 & 0.082 & 0.122 & 0.284 & 0.257 & 0.121 \\
\hline & $(0.098)$ & $(0.118)$ & & $(0.097)$ & $(0.205)$ & \\
\hline \multirow[t]{2}{*}{ \% HBV Core } & 0.033 & 0.022 & 0.197 & 0.019 & 0.015 & 0.094 \\
\hline & $(0.040)$ & $(0.039)$ & & $(0.028)$ & $(0.032)$ & \\
\hline \multirow[t]{2}{*}{ \% HBV Sur. Ant. } & 0.009 & 0.010 & -0.022 & 0.007 & 0.005 & 0.094 \\
\hline & (0.012) & $(0.044)$ & & (0.013) & (0.017) & \\
\hline
\end{tabular}

This article is protected by copyright. All rights reserved. 


\begin{tabular}{|c|c|c|c|c|c|c|}
\hline \multirow[t]{2}{*}{ \% HCV Sero. } & 0.021 & 0.014 & 0.205 & 0.010 & 0.007 & 0.176 \\
\hline & $(0.018)$ & $(0.029)$ & & $(0.011)$ & $(0.013)$ & \\
\hline \multirow[t]{2}{*}{$\%$ VAD } & 0.273 & 0.243 & 0.036 & 0.013 & 0.008 & 0.181 \\
\hline & $(0.814)$ & $(0.220)$ & & $(0.020)$ & (0.019) & \\
\hline \multirow{3}{*}{$\begin{array}{c}\text { \% Expanded } \\
\text { Donor }\end{array}$} & 0.476 & 0.332 & $0.319 *$ & 0.473 & 0.362 & $0.279 *$ \\
\hline & & & & & & \\
\hline & $(0.315)$ & $(0.323)$ & & $(0.264)$ & $(0.297)$ & \\
\hline \multirow[t]{2}{*}{ \% Hypertension } & 0.806 & 0.781 & 0.088 & 0.646 & 0.674 & -0.179 \\
\hline & $(0.164)$ & $(0.231)$ & & $(0.074)$ & $(0.143)$ & \\
\hline \multirow[t]{2}{*}{$\%$ PRA $>80$} & 0.058 & 0.054 & 0.039 & 0.052 & 0.075 & -0.140 \\
\hline & $(0.054)$ & $(0.088)$ & & (0.054) & $(0.154)$ & \\
\hline Number of Obs. & 10,108 & 2,595 & & 11,520 & 2,564 & \\
\hline
\end{tabular}

Table 2: Identification Test Results. All coefficients are expressed as incidence rate ratios and the standard errors have been clustered at the regional DSA managed by each of the OPOs. Panel A: parameter estimates for Equation 5. Panel B: parameter estimates for Equation 6. Panel C: parameter estimates for Equation 7. ***indicates statistically significant at the $1 \%$ level, $* *$ indicates statistically significant at the $5 \%$ level and *indicates statistically significant at the $10 \%$ level.

This article is protected by copyright. All rights reserved. 
Panel A

\begin{tabular}{|c|c|c|c|c|}
\hline \multirow[t]{2}{*}{ Trend $_{t} \times$ Enrolled $_{i}$} & $1.0115^{*}$ & 1.0025 & $1.0125^{*}$ & 1.0029 \\
\hline & $(0.007)$ & $(0.004)$ & $(0.007)$ & $(0.004)$ \\
\hline & & Controls & & \\
\hline Center FE & No & Yes & No & Yes \\
\hline Mnth/Yr FE & No & No & Yes & Yes \\
\hline \multirow[t]{2}{*}{ Pseudo $R^{2}$} & 0.2162 & 0.4092 & 0.2215 & 0.4135 \\
\hline & & Panel B & & \\
\hline \multirow[t]{3}{*}{ Trend $_{t} \times$ Filed $_{i}$} & 1.0002 & 1.0001 & 1.0004 & 1.0002 \\
\hline & $(0.003)$ & $(0.001)$ & $(0.003)$ & $(0.002)$ \\
\hline & & Controls & & \\
\hline Center FE & No & Yes & No & Yes \\
\hline Mnth/Yr FE & No & No & Yes & Yes \\
\hline Pseudo $R^{2}$ & 0.2226 & 0.4092 & 0.2277 & 0.4135 \\
\hline & & Panel C & & \\
\hline
\end{tabular}

This article is protected by copyright. All rights reserved. 


$\begin{array}{ccccc}\text { Trend }_{t} \times \text { Enrolled }_{i} & 1.0147^{*} & 1.0029 & 1.0155^{*} & 1.0033 \\ & (0.008) & (0.004) & (0.008) & (0.004) \\ \text { Trend }_{t} \times \text { Filed }_{i} & 0.9966 & 0.9996 & 0.9967 & 0.9996 \\ & (0.003) & (0.002) & (0.003) & \\ \text { Center FE } & & & & \\ \text { Mnth/Yr FE } & \text { Controls } & & & \text { Yes } \\ \text { Pseudo } R^{2} & \text { No } & \text { Yes } & \text { No } & \text { Yes }\end{array}$

Table 3: Regression Results: 1-year Graft Survival CMS CoP. All coefficients are expressed as incidence rate ratios and the standard errors have been clustered at the regional DSA managed by each of the OPOs. Panel A: parameter estimates for Equation 1. Panel B: parameter estimates for Equation 2. Panel C: parameter estimates for Equation 3. Panel D: parameter estimates for Equation 4. $* * *$ indicates statistically significant at the $1 \%$ level, **indicates statistically significant at the $5 \%$ level and *indicates statistically significant at the $10 \%$ level.

Panel A

Wait $_{\text {it }}$

$1.0006 * * *$

$1.0003 * *$

$1.0006^{* * *}$

$1.0004^{* *}$

(0.000)

(0.000)

(0.000)

(0.000)

This article is protected by copyright. All rights reserved. 


\begin{tabular}{|c|c|c|c|c|}
\hline$C M S_{\text {graft }}$ & $0.7526 * *$ & $0.8684 * * *$ & $0.7556^{* *}$ & $0.8686 * * *$ \\
\hline & (0.087) & $(0.032)$ & $(0.086)$ & (0.031) \\
\hline \multirow[t]{3}{*}{$N L D A C_{i t, \text { enrolled }}$} & $1.3662 * * *$ & $1.1382 * * *$ & $1.7722 * * *$ & $1.2180 * * *$ \\
\hline & (0.095) & $(0.046)$ & (0.198) & $(0.070)$ \\
\hline & & Controls & & \\
\hline Center FE & No & Yes & No & Yes \\
\hline Mnth/Yr FE & No & No & Yes & Yes \\
\hline \multirow[t]{2}{*}{ Pseudo $R^{2}$} & 0.2197 & 0.4058 & 0.2253 & 0.4109 \\
\hline & & Panel B & & \\
\hline \multirow[t]{2}{*}{ Wait $_{i t}$} & $1.0006 * * *$ & $1.0003^{*}$ & $1.0006 * * *$ & $1.0003^{* *}$ \\
\hline & $(0.000)$ & $(0.000)$ & $(0.000)$ & $(0.000)$ \\
\hline \multirow[t]{2}{*}{$C M S_{\text {graft }}$} & $0.7780 * *$ & $0.8737 * * *$ & $0.7815^{* *}$ & $0.8747 * * *$ \\
\hline & (0.091) & $(0.033)$ & $(0.091)$ & $(0.032)$ \\
\hline \multirow[t]{2}{*}{$N L D A C_{i t, \text { enrolled }}$} & 1.0863 & 1.0632 & $1.4942 * * *$ & $1.1781 * * *$ \\
\hline & (0.082) & $(0.046)$ & (0.157) & $(0.066)$ \\
\hline
\end{tabular}

This article is protected by copyright. All rights reserved. 


\begin{tabular}{|c|c|c|c|c|}
\hline \multirow[t]{2}{*}{$\left(N L D A C_{i t, \text { enrolled }}\right) \times\left(N L D A C_{i t, \text { filed }}\right)$} & $1.3368 * * *$ & $1.1052^{*}$ & $1.4445 * * *$ & $1.1349 * *$ \\
\hline & (0.119) & $(0.057)$ & (0.147) & $(0.071)$ \\
\hline \multicolumn{5}{|c|}{ Controls } \\
\hline Center FE & No & Yes & No & Yes \\
\hline Mnth/Yr FE & No & No & Yes & Yes \\
\hline \multirow[t]{2}{*}{ Pseudo $R^{2}$} & 0.2314 & 0.4060 & 0.2377 & 0.4111 \\
\hline & & Panel C & & \\
\hline \multirow[t]{2}{*}{ Wait $_{i t}$} & $1.0005^{* * *}$ & $1.0003^{*}$ & $1.0005 * * *$ & $1.0003 * *$ \\
\hline & $(0.000)$ & $(0.000)$ & $(0.000)$ & $(0.000)$ \\
\hline \multirow[t]{2}{*}{$C M S_{\text {graft }}$} & $0.7790 * *$ & $0.8713 * * *$ & $0.7807 * *$ & $0.8714 * * *$ \\
\hline & $(0.087)$ & $(0.032)$ & $(0.086)$ & $(0.031)$ \\
\hline \multirow[t]{2}{*}{$N L D A C_{i t, \text { enrolled }}$} & 1.0005 & 1.0570 & $1.4483^{* * *}$ & $1.1805^{* * *}$ \\
\hline & $(0.069)$ & $(0.044)$ & $(0.148)$ & $(0.067)$ \\
\hline \multirow[t]{2}{*}{$\left(N L D A C_{i t, \text { enrolled }}\right) \times\left(N L D A C_{i t, \text { active }}\right)$} & $1.5805^{* * *}$ & $1.1249 * * *$ & $1.6497 * * *$ & $1.1456^{* * *}$ \\
\hline & $(0.124)$ & $(0.047)$ & $(0.142)$ & $(0.054)$ \\
\hline
\end{tabular}




\section{Controls}

\begin{tabular}{|c|c|c|c|c|}
\hline Center FE & No & Yes & No & Yes \\
\hline Mnth/Yr FE & No & No & Yes & Yes \\
\hline \multirow[t]{2}{*}{ Pseudo $R^{2}$} & 0.2368 & 0.4062 & 0.2433 & 0.4114 \\
\hline & & Panel D & & \\
\hline \multirow[t]{2}{*}{ Wait $_{i t}$} & $1.0005^{* * *}$ & $1.0003^{*}$ & $1.0005^{* * *}$ & $1.0003^{* *}$ \\
\hline & $(0.000)$ & $(0.000)$ & $(0.000)$ & $(0.000)$ \\
\hline \multirow[t]{2}{*}{$C M S_{\text {graft }}$} & $0.7721^{* *}$ & $0.8707^{* * *}$ & $0.7762 * *$ & $0.8715^{* * *}$ \\
\hline & $(0.087)$ & $(0.033)$ & $(0.086)$ & $(0.032)$ \\
\hline \multirow[t]{2}{*}{$N L D A C_{i t, \text { enrolled }}$} & 1.0808 & 1.0618 & $1.4909 * * *$ & $1.1801^{* * *}$ \\
\hline & $(0.082)$ & $(0.046)$ & $(0.153)$ & $(0.066)$ \\
\hline \multirow[t]{2}{*}{$\left(N L D A C_{i t, \text { enrolled }}\right) \times\left(N L D A C_{i t, \text { filed }}\right)$} & $0.7820 * *$ & 0.9835 & $0.8331^{*}$ & 1.0028 \\
\hline & $(0.076)$ & $(0.058)$ & $(0.085)$ & $(0.068)$ \\
\hline$\left(N L D A C_{i t, \text { enrolled }}\right) \times\left(N L D A C_{i t, \text { filed }}\right)$ & $1.8430 * * *$ & $1.1371 * * *$ & $1.8390 * * *$ & $1.1437^{* * *}$ \\
\hline
\end{tabular}

This article is protected by copyright. All rights reserved. 


\begin{tabular}{|c|c|c|c|c|}
\hline$\times\left(N L D A C_{i t, \text { active }}\right)$ & $(0.172)$ & $(0.054)$ & $(0.172)$ & $(0.055)$ \\
\hline & & Controls & & \\
\hline Center FE & No & Yes & No & Yes \\
\hline Mnth/Yr FE & No & No & Yes & Yes \\
\hline Pseudo $R^{2}$ & 0.2375 & 0.4062 & 0.2436 & 0.4114 \\
\hline
\end{tabular}

Table 4: Regression Results: 1-year Patient Survival CMS CoP. All coefficients are expressed as incidence rate ratios and the standard errors have been clustered at the regional DSA managed by each of the OPOs. Panel A: parameter estimates for Equation 1. Panel B: parameter estimates for Equation 2. Panel C: parameter estimates for Equation 3. Panel D: parameter estimates for Equation 4. $* * *$ indicates statistically significant at the $1 \%$ level, **indicates statistically significant at the $5 \%$ level and *indicates statistically significant at the $10 \%$ level.

\begin{tabular}{|c|c|c|c|c|}
\hline & & Panel A & & \\
\hline \multirow[t]{2}{*}{ Wait $_{i t}$} & $1.0006 * * *$ & $1.0003 *$ & $1.0006 * * *$ & $1.0003^{* *}$ \\
\hline & $(0.000)$ & $(0.000)$ & $(0.000)$ & $(0.000)$ \\
\hline \multirow[t]{2}{*}{$C M S_{\text {patient }}$} & 1.0537 & $0.8663 * * *$ & 1.0586 & $0.8716^{* * *}$ \\
\hline & $(0.132)$ & $(0.038)$ & $(0.134)$ & (0.039) \\
\hline$N L D A C_{i t, \text { enrolled }}$ & $1.3724 * * *$ & $1.1378^{* * *}$ & $1.7843 * * *$ & $1.2216^{* * *}$ \\
\hline
\end{tabular}

This article is protected by copyright. All rights reserved. 
Center FE

Mnth/Yr FE

Pseudo $R^{2}$

0.2187

No

No

Wait $_{i t}$

$$
C M S_{\text {patient }}
$$

$N L D A C_{i t, \text { enrolled }}$

1.0824

(0.082)

$1.3507^{* * *}$

(0.118)

$1.0006^{* * *}$

$(0.000)$

1.0659

(0.122)
Yes

No

0.4059

Panel B

(0.037)

1.0604

$(0.045)$

$1.1090 * *$

(0.056)

(0.146)
Yes

Yes

0.4109

$1.0003^{* *}$

(0.000)

$0.8698^{* * *}$

(0.038)

$1.1796 * * *$

(0.065)

$1.1416^{* *}$

(0.070)

Controls

This article is protected by copyright. All rights reserved. 


\begin{tabular}{|c|c|c|c|c|}
\hline Center FE & No & Yes & No & Yes \\
\hline Mnth/Yr FE & No & No & Yes & Yes \\
\hline \multirow[t]{2}{*}{ Pseudo $R^{2}$} & 0.2307 & 0.4061 & 0.2370 & 0.4112 \\
\hline & & Panel C & & \\
\hline \multirow[t]{2}{*}{ Wait $_{i t}$} & $1.0005^{* * *}$ & $1.0003 *$ & $1.0005^{* * *}$ & $1.0003 * *$ \\
\hline & $(0.000)$ & $(0.000)$ & $(0.000)$ & $(0.000)$ \\
\hline \multirow[t]{2}{*}{$C M S_{\text {patient }}$} & 1.0670 & $0.8677^{* * *}$ & 1.0639 & $0.8714^{* * *}$ \\
\hline & $(0.115)$ & $(0.037)$ & $(0.114)$ & $(0.037)$ \\
\hline \multirow[t]{2}{*}{$N L D A C_{i t, \text { enrolled }}$} & 1.0006 & 1.0563 & $1.4516^{* * *}$ & $1.1835^{* * *}$ \\
\hline & $(0.069)$ & $(0.043)$ & (0.153) & $(0.067)$ \\
\hline \multirow[t]{3}{*}{$\left.N L D A C_{i t, \text { enrolled }}\right) \times\left(N L D A C_{i t, \text { active }}\right)$} & $1.5884^{* * *}$ & $1.1256^{* * *}$ & $1.6569 * * *$ & $1.1472^{* * *}$ \\
\hline & $(0.123)$ & $(0.046)$ & $(0.140)$ & $(0.053)$ \\
\hline & & Controls & & \\
\hline Center FE & No & Yes & No & Yes \\
\hline Mnth/Yr FE & No & No & Yes & Yes \\
\hline
\end{tabular}

This article is protected by copyright. All rights reserved. 


\begin{tabular}{|c|c|c|c|c|}
\hline Pseudo $R^{2}$ & 0.2361 & 0.4063 & 0.2426 & 0.4114 \\
\hline & & Panel D & & \\
\hline \multirow[t]{2}{*}{ Wait $_{i t}$} & $1.0005^{* * *}$ & $1.0003^{*}$ & $1.0005^{* * *}$ & $1.0003 * *$ \\
\hline & $(0.000)$ & $(0.000)$ & $(0.000)$ & $(0.000)$ \\
\hline \multirow[t]{2}{*}{$C M S_{\text {patient }}$} & 1.0635 & $0.8677^{* * *}$ & 1.0644 & $0.8712^{* * *}$ \\
\hline & $(0.114)$ & $(0.037)$ & (0.113) & $(0.037)$ \\
\hline \multirow[t]{2}{*}{$N L D A C_{i t, \text { enrolled }}$} & 1.0763 & 1.0590 & $1.4917^{* * *}$ & $1.1815^{* * *}$ \\
\hline & $(0.082)$ & $(0.045)$ & $(0.158)$ & $(0.065)$ \\
\hline \multirow[t]{2}{*}{$\left(N L D A C_{i t, \text { enrolled }}\right) \times\left(N L D A C_{i t, \text { filed }}\right)$} & $0.7920 * *$ & 0.9906 & $0.8421^{*}$ & 1.0135 \\
\hline & $(0.077)$ & $(0.057)$ & $(0.086)$ & $(0.067)$ \\
\hline$\left(N L D A C_{i t, \text { enrolled }}\right) \times\left(N L D A C_{i t, \text { filed }}\right)$ & $1.8384^{* * *}$ & $1.1325^{* * *}$ & $1.8357^{* * *}$ & $1.1379 * * *$ \\
\hline \multirow[t]{2}{*}{$\times\left(N L D A C_{i t, a c t i v e}\right)$} & $(0.172)$ & $(0.053)$ & $(0.173)$ & $(0.054)$ \\
\hline & & Controls & & \\
\hline Center FE & No & Yes & No & Yes \\
\hline
\end{tabular}

This article is protected by copyright. All rights reserved. 


$\begin{array}{ccccc}\text { Mnth/Yr FE } & \text { No } & \text { No } & \text { Yes } & \text { Yes } \\ \text { Pseudo } R^{2} & 0.2367 & 0.4063 & 0.2428 & 0.4114\end{array}$

Table 5: Regression Results: 1-year Graft Survival CMS CoP. All coefficients are expressed as incidence rate ratios and the standard errors have been clustered at the regional DSA managed by each of the OPOs. Panel A: parameter estimates for Equation 1. Panel B: parameter estimates for Equation 2. Panel C: parameter estimates for Equation 3. Panel D: parameter estimates for Equation 4. ${ }^{* *}$ indicates statistically significant at the $1 \%$ level, $* *$ indicates statistically significant at the $5 \%$ level and *indicates statistically significant at the $10 \%$ level.

Panel A

\begin{tabular}{|c|c|c|c|c|}
\hline & 1st Quartile & 2nd Quartile & 3rd Quartile & 4th Quartile \\
\hline \multirow[t]{3}{*}{$N L D A C_{i t, \text { enrolled }}$} & 1.0422 & 1.0724 & 1.0342 & $1.9369 * * *$ \\
\hline & $(0.069)$ & $(0.078)$ & $(0.110)$ & $(0.482)$ \\
\hline & \multicolumn{3}{|c|}{ Controls } & \\
\hline Center FE & Yes & Yes & Yes & Yes \\
\hline Mnth/Yr FE & Yes & Yes & Yes & Yes \\
\hline Pseudo $R^{2}$ & 0.4112 & & & \\
\hline
\end{tabular}

Panel B

This article is protected by copyright. All rights reserved. 


\begin{tabular}{|c|c|c|c|c|}
\hline & 1st Quartile & 2nd Quartile & 3rd Quartile & 4th Quartile \\
\hline$\left(N L D A C_{i t, \text { enrolled }}\right)$ & 1.0361 & $1.12266^{*}$ & 1.1005 & $1.5643^{* *}$ \\
\hline$\times\left(N L D A C_{i t, \text { filed }}\right)$ & $(0.056)$ & $(0.135)$ & $(0.096)$ & $(0.291)$ \\
\hline \multicolumn{5}{|c|}{ Controls } \\
\hline Center FE & Yes & Yes & Yes & Yes \\
\hline Mnth/Yr FE & Yes & Yes & Yes & Yes \\
\hline Pseudo $R^{2}$ & 0.4116 & & & \\
\hline \multicolumn{5}{|c|}{ Panel C } \\
\hline & 1st Quartile & 2nd Quartile & 3rd Quartile & 4th Quartile \\
\hline$\left(N L D A C_{i t, \text { enrolled }}\right)$ & 1.0555 & $1.1655^{* *}$ & $1.2701 * * *$ & $1.5533^{* * *}$ \\
\hline$\times\left(N L D A C_{i t, \text { active }}\right)$ & (0.049) & $(0.088)$ & $(0.101)$ & (0.195) \\
\hline \multicolumn{5}{|c|}{ Controls } \\
\hline Center FE & Yes & Yes & Yes & Yes \\
\hline Mnth/Yr FE & Yes & Yes & Yes & Yes \\
\hline
\end{tabular}

This article is protected by copyright. All rights reserved. 


\begin{tabular}{|c|c|c|c|c|}
\hline Pseudo $R^{2}$ & 0.4118 & & & \\
\hline \multicolumn{5}{|c|}{ Panel D } \\
\hline & 1st Quartile & 2nd Quartile & 3rd Quartile & 4th Quartile \\
\hline$\left(N L D A C_{i t, \text { enrolled }}\right)$ & 1.1111 & 1.0768 & $1.4229 * * *$ & $1.3690 * *$ \\
\hline$\times\left(N L D A C_{i t, f i l e d}\right)$ & $(0.081)$ & $(0.070)$ & $(0.141)$ & $(0.206)$ \\
\hline \multicolumn{5}{|l|}{$\times\left(N L D A C_{i t, a c t i v e}\right)$} \\
\hline \multicolumn{5}{|c|}{ Controls } \\
\hline Center FE & Yes & Yes & Yes & Yes \\
\hline Mnth/Yr FE & Yes & Yes & Yes & Yes \\
\hline Pseudo $R^{2}$ & 0.4119 & & & \\
\hline
\end{tabular}

Table 6: Regression Results: 1-year Patient Survival CMS CoP. All coefficients are expressed as incidence rate ratios and the standard errors have been clustered at the regional DSA managed by each of the OPOs. Panel A: parameter estimates for Equation 1. Panel B: parameter estimates for Equation 2. Panel C: parameter estimates for Equation 3. Panel D: parameter estimates for Equation 4. ${ }^{* *}$ indicates statistically significant at the $1 \%$ level, $* *$ indicates statistically significant at the $5 \%$ level and *indicates statistically significant at the $10 \%$ level.

This article is protected by copyright. All rights reserved. 
Panel A

\begin{tabular}{|c|c|c|c|c|}
\hline & 1st Quartile & 2nd Quartile & 3rd Quartile & 4th Quartile \\
\hline \multirow[t]{3}{*}{$N L D A C_{i t, \text { enrolled }}$} & 1.0430 & 1.0770 & 1.0340 & $1.9326 * * *$ \\
\hline & $(0.068)$ & $(0.078)$ & (0.109) & $(0.489)$ \\
\hline & & Controls & & \\
\hline Center FE & Yes & Yes & Yes & Yes \\
\hline Mnth/Yr FE & Yes & Yes & Yes & Yes \\
\hline \multirow[t]{3}{*}{ Pseudo $R^{2}$} & 0.4112 & & & \\
\hline & & Panel B & & \\
\hline & 1st Quartile & 2nd Quartile & 3rd Quartile & 4th Quartile \\
\hline$\left(N L D A C_{i t, \text { enrolled }}\right)$ & 1.0391 & $1.1230 * *$ & 1.1052 & $1.5829 * * *$ \\
\hline \multirow[t]{2}{*}{$\times\left(N L D A C_{i t, f i l e d}\right)$} & $(0.058)$ & $(0.130)$ & $(0.097)$ & $(0.296)$ \\
\hline & & Controls & & \\
\hline Center FE & Yes & Yes & Yes & Yes \\
\hline Mnth/Yr FE & Yes & Yes & Yes & Yes \\
\hline
\end{tabular}

This article is protected by copyright. All rights reserved. 


\begin{tabular}{|c|c|c|c|c|}
\hline Pseudo $R^{2}$ & 0.4116 & & & \\
\hline \multicolumn{5}{|c|}{ Panel C } \\
\hline & 1st Quartile & 2nd Quartile & 3rd Quartile & 4th Quartile \\
\hline$\left(N L D A C_{i t, \text { enrolled }}\right)$ & 1.0549 & $1.1661 * *$ & $1.2638 * * *$ & $1.5576 * * *$ \\
\hline$\times\left(N L D A C_{i t, \text { active }}\right)$ & (0.049) & $(0.086)$ & $(0.100)$ & $(0.198)$ \\
\hline \multicolumn{5}{|c|}{ Controls } \\
\hline Center FE & Yes & Yes & Yes & Yes \\
\hline Mnth/Yr FE & Yes & Yes & Yes & Yes \\
\hline Pseudo $R^{2}$ & 0.4118 & & & \\
\hline \multicolumn{5}{|c|}{ Panel D } \\
\hline & 1st Quartile & 2nd Quartile & 3rd Quartile & 4th Quartile \\
\hline$\left(N L D A C_{i t, \text { enrolled }}\right)$ & 1.1042 & 1.0739 & $1.4033^{* * *}$ & $1.3565^{* *}$ \\
\hline$\times\left(N L D A C_{i t, \text { filed }}\right)$ & $(0.078)$ & $(0.70)$ & $(0.138)$ & $(0.201)$ \\
\hline
\end{tabular}

This article is protected by copyright. All rights reserved. 


\section{Controls}

$\begin{array}{lcccc}\text { Center FE } & \text { Yes } & \text { Yes } & \text { Yes } & \text { Yes } \\ \text { Mnth/Yr FE } & \text { Yes } & \text { Yes } & \text { Yes } & \text { Yes } \\ \text { Pseudo } R^{2} & 0.4120 & & & \end{array}$

Table 7: Regression Results: Left column represents the estimated treatment effect on living donor kidney transplants. Right column illustrates the treatment effect on deceased donor kidney transplants. All regressions contain the same covariate controls used in our estimation of the NLDAC treatment effects. All coefficients are expressed as incidence rate ratios and the standard errors have been clustered at the regional DSA managed by each of the OPOs. ${ }^{* *}$ indicates statistically significant at the $1 \%$ level, $* *$ indicates statistically significant at the $5 \%$ level and *indicates statistically significant at the $10 \%$ level.

CMS Total Graft Survival Model

\begin{tabular}{|c|c|c|c|c|c|c|c|c|}
\hline Variable & Liv. Kidney & $\begin{array}{l}\text { Dec. } \\
\text { Kidney }\end{array}$ & Liv. Kidney & $\begin{array}{l}\text { Dec. } \\
\text { Kidney }\end{array}$ & Liv. Kidney & $\begin{array}{l}\text { Dec. } \\
\text { Kidney }\end{array}$ & Liv. Kidney & $\begin{array}{c}\text { Dec. } \\
\text { Kidney }\end{array}$ \\
\hline \multirow[t]{2}{*}{$N L D A C_{i t, \text { enrolled }}$} & $1.2180 * * *$ & 1.1289 & $1.1781^{* * *}$ & 1.1262 & $1.1805^{* * *}$ & 1.1284 & $1.1801^{* * *}$ & 1.1261 \\
\hline & $(0.070)$ & (0.111) & $(0.067)$ & (0.108) & $(0.067)$ & (0.109) & (0.066) & (0.108) \\
\hline$\left(N L D A C_{i t, \text { enrolled }}\right)$ & & & $1.1349 * *$ & 1.0072 & & & 1.0028 & 1.0109 \\
\hline
\end{tabular}

This article is protected by copyright. All rights reserved. 

$\times\left(N L D A C_{i t, f i l e d}\right)$
(0.071)
(0.036)
(0.068) (0.047)
$\left(N L D A C_{i t, \text { enrolled }}\right)$
$1.1456 * * * \quad 1.0015$
$\times\left(N L D A C_{i t, a c t i v e}\right.$
(0.054) (0.027)
$\left(N L D A C_{i t, \text { enrolled }}\right)$
$1.1437 * * * \quad 0.9958$
$\times\left(N L D A C_{i t, \text { filed }}\right)$
$(0.055) \quad(0.036)$
$\times\left(N L D A C_{i t, a c t i v e}\right)$
Controls

\begin{tabular}{|c|c|c|c|c|c|c|c|c|}
\hline Center FE & Yes & Yes & Yes & Yes & Yes & Yes & Yes & Yes \\
\hline Mnth/Yr FE & Yes & Yes & Yes & Yes & Yes & Yes & Yes & Yes \\
\hline Pseudo $R^{2}$ & 0.4109 & 0.3941 & 0.4111 & 0.3941 & 0.4114 & 0.3941 & 0.4114 & 0.3941 \\
\hline Num. of Obs. & 26,769 & 26,769 & 26,769 & 26,769 & 26,769 & 26,769 & 26,769 & 26,769 \\
\hline
\end{tabular}

$\begin{array}{cccccccccc}\text { Variable } & \text { Liv. Kidney } & \begin{array}{c}\text { Dec. } \\ \text { Kidney }\end{array} & \text { Liv. Kidney } & \begin{array}{c}\text { Dec. } \\ \text { Kidney }\end{array} & \text { Liv. Kidney } & \text { Dec. } & \text { Liv. Kidney } & \text { Dec. } \\ & & & & \text { Kidney } & \text { Kidney } \\ N L D A C_{i t, \text { nnolled }} & 1.2216^{* * *} & 1.1319 & 1.1835^{* * *} & 1.1273 & 1.1815^{* * *} & 1.1318 & 1.1815^{* * *} & 1.1270\end{array}$

This article is protected by copyright. All rights reserved. 


$$
\begin{aligned}
& \begin{array}{lllllll}
(0.070) & (0.115) & (0.067) & (0.111) & (0.065) & (0.113) & (0.065)
\end{array} \\
& \left(N L D A C_{i t, \text { enrolled }}\right) \\
& 1.1416^{* *} \quad 1.0125 \\
& 1.0135 \quad 1.0230 \\
& \times\left(N L D A C_{i t, \text { filed }}\right. \\
& \begin{array}{llll}
(0.070) \quad(0.034) & (0.067) \quad(0.048)
\end{array} \\
& \left(N L D A C_{i t, \text { enrolled }}\right) \\
& 1.1472^{* * *} \quad 1.0003 \\
& \times\left(N L D A C_{i t, a c t i v e}\right) \\
& \left(N L D A C_{i t, \text { enrolled }}\right) \\
& \times\left(N L D A C_{i t, \text { filed }}\right) \\
& \times\left(N L D A C_{i t, a c t i v e}\right) \\
& 1.1379 * * * \quad 0.9884 \\
& \text { (0.032) (0.027) }
\end{aligned}
$$$$
\text { Controls }
$$

$\begin{array}{ccccccccc}\text { Center FE } & \text { Yes } & \text { Yes } & \text { Yes } & \text { Yes } & \text { Yes } & \text { Yes } & \text { Yes } & \text { Yes } \\ \text { Mnth/YrFE } & \text { Yes } & \text { Yes } & \text { Yes } & \text { Yes } & \text { Yes } & \text { Yes } & \text { Yes } & \text { Yes }\end{array}$

$\begin{array}{llllllllll}\text { Pseudo } R^{2} & 0.4109 & 0.3938 & 0.4114 & 0.3938 & 0.4114 & 0.3938 & 0.4114 & 0.3938\end{array}$

$\begin{array}{llllllll}\text { Num. of Obs. } \quad 26,769 & 26,769 & 26,769 & 26,769 & 26,769 & 26,769 & 26,769 & 26,769\end{array}$

Table 8: Regression Results: Left column represents the estimated treatment effect on living donor kidney transplants for those centers that conducted both living donor kidney transplants and thoracic transplants (119 
centers). Right column illustrates the treatment effect on thoracic transplants (129 centers). All coefficients are expressed as incidence rate ratios and the standard errors have been clustered at the regional DSA managed by each of the OPOs. ${ }^{* *}$ indicates statistically significant at the $1 \%$ level, ${ }^{* *}$ indicates statistically significant at the $5 \%$ level and *indicates statistically significant at the $10 \%$ level.

\begin{tabular}{|c|c|c|c|c|c|c|c|c|}
\hline \multicolumn{9}{|c|}{ CMS Total Graft Survival Model } \\
\hline Variable & Liv. Kidney & Thoracic & Liv. Kidney & Thoracic & Liv. Kidney & Thoracic & Liv. Kidney & Thoracic \\
\hline$N L D A C_{i t, \text { enrolled }}$ & 0.9610 & 0.9680 & 0.9509 & 0.9965 & 0.9436 & 0.9988 & 0.9491 & 0.9955 \\
\hline & $(0.058)$ & $(0.186)$ & $(0.057)$ & $(0.188)$ & $(0.058)$ & $(0.197)$ & $(0.057)$ & $(0.187)$ \\
\hline$\left(N L D A C_{i t, \text { enrolled }}\right)$ & & & 1.1084 & 0.9479 & & & 0.8979 & 1.0110 \\
\hline$\times\left(N L D A C_{i t, f i l e d}\right.$ & & & $(0.068)$ & $(0.047)$ & & & $(0.071)$ & $(0.102)$ \\
\hline$\left(N L D A C_{i t, \text { enrolled }}\right)$ & & & & & $1.1462 * * *$ & 0.9358 & & \\
\hline$\times\left(N L D A C_{i t, a c t i v e}\right)$ & & & & & $(0.055)$ & $(0.050)$ & & \\
\hline$\left(N L D A C_{i t, \text { enrolled }}\right)$ & & & & & & & $1.2211 * * *$ & 0.9307 \\
\hline$\times\left(N L D A C_{i t, \text { filed }}\right)$ & & & & & & & $(0.074)$ & $(0.085)$ \\
\hline
\end{tabular}

This article is protected by copyright. All rights reserved. 


\section{Controls}

\begin{tabular}{|c|c|c|c|c|c|c|c|c|}
\hline Center FE & Yes & Yes & Yes & Yes & Yes & Yes & Yes & Yes \\
\hline Mnth/Yr FE & Yes & Yes & Yes & Yes & Yes & Yes & Yes & Yes \\
\hline Pseudo $R^{2}$ & 0.3583 & 0.4471 & 0.3584 & 0.4471 & 0.3588 & 0.4472 & 0.3589 & 0.4472 \\
\hline Num. of Obs. & 13,937 & 15,480 & 13,937 & 15,480 & 13,937 & 15,480 & 13,937 & 15,480 \\
\hline \multicolumn{9}{|c|}{ CMS Total Patient Survival Model } \\
\hline Variable & $\begin{array}{c}\text { Liv. } \\
\text { Kidney }\end{array}$ & Thoracic & Liv. Kidney & Thoracic & Liv. Kidney & Thoracic & Liv. Kidney & Thoracic \\
\hline \multirow[t]{2}{*}{$N L D A C_{i t, \text { enrolled }}$} & 0.9676 & 0.9685 & 0.9561 & 0.9975 & 0.9499 & 0.9991 & 0.9547 & 0.9967 \\
\hline & $(0.057)$ & $(0.186)$ & $(0.056)$ & (0.189) & $(0.057)$ & $(0.197)$ & $(0.056)$ & $(0.188)$ \\
\hline$\left(N L D A C_{i t, \text { enrolled }}\right)$ & & & 1.0929 & 0.9471 & & & 0.9142 & 1.0081 \\
\hline$\times\left(N L D A C_{i t, \text { filed }}\right)$ & & & (0.069) & $(0.047)$ & & & $(0.072)$ & (0.098) \\
\hline$\left(N L D A C_{i t, \text { enrolled }}\right)$ & & & & & $1.1470 * * *$ & 0.9363 & & \\
\hline$\times\left(N L D A C_{i t, \text { active }}\right)$ & & & & & $(0.056)$ & $(0.049)$ & & \\
\hline$\left(N L D A C_{i t, \text { enrolled }}\right)$ & & & & & & & $1.2091^{* * *}$ & 0.9325 \\
\hline
\end{tabular}

This article is protected by copyright. All rights reserved. 


$$
\begin{aligned}
& \times\left(N L D A C_{i t, f i l e d}\right) \\
& \times\left(N L D A C_{i t, a c t i v e}\right)
\end{aligned}
$$

\section{Controls}

$\begin{array}{ccccccccc}\text { Center FE } & \text { Yes } & \text { Yes } & \text { Yes } & \text { Yes } & \text { Yes } & \text { Yes } & \text { Yes } & \text { Yes } \\ \text { Mnth/Yr FE } & \text { Yes } & \text { Yes } & \text { Yes } & \text { Yes } & \text { Yes } & \text { Yes } & \text { Yes } & \text { Yes } \\ \text { Pseudo } R^{2} & 0.3582 & 0.4470 & 0.3583 & 0.4471 & 0.3587 & 0.4472 & 0.3588 & 0.4472 \\ \text { Num. of Obs. } & 13,937 & 15,480 & 13,937 & 15,480 & 13,937 & 15,480 & 13,937 & 15,480\end{array}$

Figure 1: The number of living and deceased kidney donors and transplants from 1988-2012 (OPTN 2014). The number of deceased donors is the solid line and the number of living donors is the dashed line. The top panel contains the number of donors and the bottom panel contains the number of transplants conducted from the donor sources.

Figure 2: Participation in NLDAC by Year. Enrolled in NLDAC corresponds with our treatment variable $N L D A C_{i t, \text { enrolled }}$. Enrolled and Filed at least once with NLDAC corresponds with our treatment variable $N L D A C_{i t, \text { filed }}$. Enrolled and actively filing corresponds with our treatment variable $N L D A C_{i t, a c t i v e}$.

Figure 3: Plot of the average residuals for those centers that enrolled in NLDAC and those that did not enroll. The residuals were obtained by regressing our monthly number of organ transplants on a set of transplant-center fixed effects to de-mean the data. The top panel plots the average monthly residuals and the bottom panel aggregates up to the year. 
Figure 4: Plot of the average residuals for those centers that enrolled in NLDAC and filed a claim with them at some point in time post-NLDAC (this is a time invariant group, any center filing in the post-NLDAC period is included) and those that enrolled in NLDAC but never elected to file a claim for reimbursement from NLDAC. The residuals were obtained by regressing our monthly number of organ transplants on a set of transplant-center fixed effects to de-mean the data. The top panel plots the average monthly residuals and the bottom panel aggregates up to the year.

Figure 5: Plot of the average residuals for those centers that enrolled in NLDAC and filed a claim with them at some time post-NLDAC and those that enrolled in NLDAC but never elected to file a claim for reimbursement from NLDAC. In the post-NLDAC time period those centers that enrolled and filed a claim with NLDAC are further divided into those centers that filed in the given year and those did not in the same year. The residuals were obtained by regressing our monthly number of organ transplants on a set of transplant-center fixed effects to de-mean the data. The top panel plots the average monthly residuals and the bottom panel aggregates up to the year.

Figure 6: Plot of the monthly treatment variables. The top panel contains results for the monthly treatment variables obtained from estimating Equation 1 . The bottom panel contains results for the monthly treatment variables obtained from estimating Equation 2 . The time period varies from $t-12$ to $t+12$ months from the first month either a center enrolled in NLDAC (top panel) or the first month they filed a reimbursement claim with NLDAC (bottom panel). 